C. Dem, M. Stöhr, C.M. Arndt, A.M. Steinberg, W. Meier, Experimental Study of Turbulence-Chemistry Interactions in Perfectly and Partially Premixed Confined Swirl Flames, Zeitschrift für Physikalische Chemie 229, 569-596, 2015.

This paper was published in Zeitschrift für Physikalische Chemie and is made available as an electronic reprint with the permission of Oldenbourg Wissenschaftsverlag.

It is accessible via http://dx.doi.org/10.1515/zpch-2014-0583 


\title{
Experimental Study of Turbulence-Chemistry Interactions in Perfectly and Partially Premixed Confined Swirl Flames
}

Claudiu Dem ${ }^{1}$, Michael Stöhr ${ }^{1}$, Christoph M. Arndt ${ }^{1}$, Adam M. Steinberg ${ }^{2}$, Wolfgang Meier ${ }^{1} *$

${ }^{1}$ Deutsches Zentrum für Luft- und Raumfahrt (DLR), Institut für Verbrennungstechnik, Pfaffenwaldring 38-40, 70569 Stuttgart, Germany

${ }^{2}$ Institute for Aerospace Studies, University of Toronto, 4925 Dufferin Street, Toronto, Ontario M3H 5T6, Canada

Keywords: Swirl flames, premixed flames, gas turbine combustion, combustion diagnostics, laser Raman scattering

\begin{abstract}
A gas turbine model combustor (Turbomeca Burner) for premixed methane/air flames has been operated at atmospheric pressure in two different modes of premixing. In the partially premixed mode, fuel was injected into the air flow within the swirl generator shortly upstream of the combustion chamber while in the perfectly premixed mode fuel and air were mixed far upstream. The main objective of this work is the study of the influence of the mode of premixing on the combustion behavior. Stereoscopic particle image velocimetry has been applied for the measurement of the flow field, $\mathrm{OH}$ chemiluminescence imaging for the visualization of the flame shapes and single-shot laser Raman scattering for the determination of the joint probability density functions of major species concentrations, mixture fraction and temperature. The mixing and reaction progress and effects of turbulence-chemistry interactions are characterized by scatterplots showing the correlations between different quantities. To isolate effects of mixing from combustion instabilities that were frequently observed in this combustor, operating conditions without thermo-acoustic oscillations or coherent flow structures were chosen. While the mode of premixing had no major influence on the general flame behavior characteristic differences were observed with respect to flame anchoring, the flow field in the inner recirculation zone and the $\mathrm{CO}$ concentration level. The results further extend the data base of previous experimental and numerical investigations with this burner.
\end{abstract}

\section{Introduction}

The use of lean premixed (LP) combustion in power generation gas turbine (GT) engines has led to a significant reduction in $\mathrm{NO}_{\mathrm{x}}$ emissions $[1,2]$. However, a serious problem with LP combustion is its susceptibility to thermo-acoustic instabilities, which are driven by the combustion process and sustained by a resonant feedback mechanism coupling pressure and 
heat release [3-9]. Nevertheless, most of today's power generation GTs are operated lean premixed, and current developments for aero engines also target lean premixed (prevaporized) combustion [10].

To avoid large volumes of premixed fuel and air upstream of the combustion chamber and the risk of flashback, gaseous fuel and air are mixed in LP burners immediately before entering the combustion chamber. In swirl burners, the fuel usually is injected with high momentum into the air flow within the swirler. The time for fuel/air mixing before the onset of combustion is thus very short $(\sim 1 \mathrm{~ms})$ and perfect premixing cannot be achieved. This method of mixing is often referred to as technical premixing. Therefore, a certain degree of unmixedness is always present in GT combustion chambers. Fuel/air mixing, and resultant unmixedness, can have several significant effects on the combustion behavior.

(1) The presence of fuel-rich streaks often increases the blow-off stability of LP flames near the lean extinction limit. On the other hand, thermal $\mathrm{NO}_{\mathrm{x}}$ formation is enhanced in these regions [11]. Also, while $\mathrm{CO}$ formation is smaller in stably burning flames compared to flames with local flame extinction or unstable flame anchoring, it increases non-linearly with increasing equivalence ratio.

(2) Inhomogeneities in the distribution of the combustion temperature caused by unmixedness may persist up to the turbine inlet and lead to material damage.

(3) Equivalence ratio fluctuations at the flame front, which originate from the mode of premixing, are one of the main sources of thermo-acoustic instabilities in GTs. Variations in the heat release in the combustion chamber lead to pressure variations that influence the flow rates of fuel and air entering the combustion chamber. Because the fuel generally is injected with a higher pressure drop than the air, the fuel and air supply lines respond differently to pressure variations in the burner. This leads to a fluctuating equivalence ratio. If the convective time delay of such fluctuations from the burner to the flame zone is (nearly) in resonance with an acoustic mode of the system, periodic thermo-acoustic oscillation can occur $[8,12,13]$.

(4) The interaction between spatial or temporal equivalence ratio fluctuations and the flame behavior becomes even more complex if coherent flow structures like a precessing vortex core influence the mixing and reaction rates or interact with thermo-acoustic oscillations [1417].

Although the effects listed above are known in principle, it is difficult to quantify the degree of unmixedness or its spatial and temporal distributions. For non-reacted mixtures, several chemical-analytical or optical methods are available. Chemical-analytical methods for the determination of fuel/air compositions in GT burners mostly rely on suction probe techniques, which suffer from a limited temporal and spatial resolution. Optical methods can be applied without physical probes if optical access to the flame is provided. Sensors based on absorption spectroscopy have been used in laboratory and practical combustors [18,19]. Laser-induced fluorescence (LIF) of naturally occurring major species is generally not applicable for 
components present in natural gas/air flames because of the lack of suitable electronic transitions. However, tracers have frequently been used to image fuel or fuel/air mixtures by LIF in combustion systems [20-22], including measurements with high temporal resolution using high-speed laser arrangements in a GT model combustor [23]. However, the techniques mentioned above are not suited to measure equivalence ratio (or mixture fraction, which is the fraction of mass in a sample originating from the fuel stream) variations with spatial and temporal resolution in reacting systems, because of the missing knowledge about the thermochemical state of the system or the lack of suitable tracers.

Determination of the equivalence ratio in the reaction zone of (partially) premixed flames is possible by exploiting chemiluminescence emissions. In recent years, a number of studies have been published in which the chemiluminescence of electronically excited species in flames, like $\mathrm{OH}, \mathrm{CH}$ or $\mathrm{CO}_{2}$, have been used to determine the equivalence ratio in laboratory and practical flames [7,19,24-26]. As a line-of-sight imaging technique, chemiluminescence imaging usually compromises spatial resolution, unless novel and more sophisticated variants of this technique are applied [27-30]. However, in all cases, signal trapping may seriously limit the quantitative evaluation of equivalence ratio measurements using chemiluminescence $[31,32]$.

The method of choice for the determination of local mixture fraction in flames is laser Raman scattering, which has often been employed with single-shot resolution in point or line measurements [33-40]. With the simultaneous measurement of all major species concentrations, the local mixing state can be determined. Temperature also can then be determined from the total number density $[41,42]$. The joint probability density functions of major species concentrations, mixture fraction, and temperature enable a detailed characterization of the mixing and reaction progress in flames and reveal effects of turbulence-chemistry interaction. Using single-shot Raman scattering, the degree of unmixedness, as well as the progress in mixing and reaction have previously been analyzed in premixed industrial GT (model) combustors at realistic operating conditions, i.e. elevated pressure, preheated air, and high turbulence level [43-45]. Those studies clearly demonstrated that, although globally very fuel-lean, frequently samples of near-stoichiometric or even fuelrich compositions are found in technically premixed flames. In the present study, this technique has been applied to measure the degree of unmixedness and to analyze the influence of mixture fraction variations on the reaction progress in a GT model combustor.

The experimental studies presented in this paper have been obtained in a model combustor (Turbomeca Burner) which has previously been used for different experimental and numerical investigations. It was designed by the company Turbomeca as a generic combustor for LP swirl flames operated with gaseous fuel and air in a range of thermal powers up to approximately $40 \mathrm{~kW}$ at atmospheric pressure [46,47]. In its original design, fuel is injected through small holes into the air flow within a radial swirler. The mixture then passes a converging nozzle before entering the combustion chamber. This design is termed technical premixing in the following. Alternatively, fuel and air can be mixed far upstream to achieve a 
perfect premixing. In the combustion chamber, an inner and outer recirculation zone are established which lead to an intense mixing of fresh gas with recirculated burned gas. This is the main mechanism for flame stabilization in turbulent swirl flames, and is applied in numerous technical combustors. At certain operating conditions the flame exhibits pronounced thermo-acoustic oscillations in the frequency range of $300 \mathrm{~Hz}$ which are accompanied by equivalence ratio fluctuations in the technically premixed flame [48]. The oscillations were generally much stronger in the technically premixed flames than in the perfectly premixed flames. Numerical simulations have been performed assuming either perfect premixing [49-51] or using the configuration with technical premixing [52-54]. Further experiments focused on the role of a precessing helical vortex core that was present at some operating conditions [17,55-57]. Some of those experiments were performed applying perfect premixing.

The investigations performed so far showed that the two configurations - perfect and technical premixing - exhibited quite different combustion characteristics, particularly with respect to thermo-acoustic instabilities. The main goal of the current study has been the determination of the differences between the two configurations with respect to reaction progress, species composition and flame shape. To separate these aspects from the influence of thermo-acoustic instabilities an operating condition has been chosen in which both flames were "quiet", i.e. without thermo-acoustic oscillations and without precessing helical flow structures. The fuel was methane, the thermal power of the flames was $25 \mathrm{~kW}$ and the equivalence ratio was $\phi=0.9$. To compare effects of unmixedness with changes in equivalence ratio, a perfectly premixed flame with $\phi=0.8$ also was studied. For each case, single-shot laser Raman scattering was applied for the simultaneous measurement of the concentrations of $\mathrm{O}_{2}, \mathrm{~N}_{2}, \mathrm{CH}_{4}, \mathrm{CO}_{2}, \mathrm{H}_{2} \mathrm{O}, \mathrm{H}_{2}$, and $\mathrm{CO}$, from which the mixture fraction and temperature were derived. To investigate a possible influence of the differently premixed flames on the flow field, particle image velocimetry was used. Further, the flame shapes were visualized by $\mathrm{OH}$ chemiluminescence imaging.

\section{Experimental}

\subsection{Burner and combustion chamber}

A schematic drawing of the combustor is presented in Fig.1, together with a photo of a typical flame. Dry air at ambient temperature was supplied via a plenum $(\varnothing=78 \mathrm{~mm})$ through 12 radial swirler vanes to the burner nozzle. The fuel (methane) was either injected into the air flow through small holes $(\varnothing=1 \mathrm{~mm})$ within the radial swirler in a jet-in-crossflow arrangement (technical premixing) or was mixed with air in a commercial premixer located approximately $2 \mathrm{~m}$ upstream of the plenum (perfect premixing). The converging nozzle consists of a central conical bluff body with the tip located at the nozzle exit plane (defined as height $\mathrm{h}=0$ ). The nozzle exit has a diameter of $27.85 \mathrm{~mm}$. More details of the swirler and nozzle geometry can be found in previous publications [46,47]. It is noted that the burner can be operated with a central injector as described in $[47,58]$ but it was not used here. 
The air and fuel flow rates were controlled by Brooks MFC 5800S electromechanical mass flow controllers and monitored with Siemens Sitrans Mass 2100 coriolis mass flow meters with an accuracy of $\pm 1.5 \%$.

The combustion chamber consisted of 4 fused silica windows of $1.7 \mathrm{~mm}$ thickness held by Inconel posts in the corners, creating a confinement with a $85 \mathrm{~mm}$ x $85 \mathrm{~mm}$ cross-section and $114 \mathrm{~mm}$ height. The exit of the vertically-oriented combustion chamber was conically shaped, leading to a short central exhaust pipe with a diameter of $40 \mathrm{~mm}$. To change the measuring location within the flames, the burner could be translated in the axial and radial directions. The accuracy of the burner position measurement was estimated to be $\pm 0.1 \mathrm{~mm}$, and the dayto-day reproducibility was better than $\pm 0.5 \mathrm{~mm}$. Table 1 summarizes the parameters of the three flames investigated. The nomenclatures PP and TP mean "perfectly premixed" and "technically premixed", respectively. The numbers 08 and 09 indicate the equivalence ratios.

\begin{tabular}{|c|c|c|c|c|c|c|c|c|}
\hline \multirow[b]{2}{*}{ Flame } & \multirow{2}{*}{$\begin{array}{c}\varphi \\
{[-]}\end{array}$} & \multirow{2}{*}{$\begin{array}{c}\mathrm{P}_{\text {th }} \\
{[\mathrm{kW}]}\end{array}$} & \multirow{2}{*}{$\begin{array}{c}\mathrm{f} \\
{[-]}\end{array}$} & \multicolumn{2}{|c|}{$\mathrm{CH}_{4}$} & \multicolumn{2}{|c|}{ Air } & \multirow{2}{*}{$\begin{array}{l}\mathrm{T}_{\mathrm{ad}} \\
{[\mathrm{K}]}\end{array}$} \\
\hline & & & & {$[\mathrm{g} / \mathrm{min}]$} & {$[\mathrm{sl} / \mathrm{min}]$} & {$[\mathrm{g} / \mathrm{min}]$} & {$[\mathrm{sl} / \mathrm{min}]$} & \\
\hline PP08 & 0.8 & 25 & 0.0447 & 30 & 41.8 & 645 & 499 & 1995 \\
\hline PP09 & 0.9 & 25 & 0.0498 & 30 & 41.8 & 574 & 444 & 2133 \\
\hline TP09 & 0.9 & 25 & 0.0498 & 30 & 41.8 & 574 & 444 & 2133 \\
\hline
\end{tabular}

Table 1: Operating conditions of the flames. $\varphi$ is the equivalence ratio, $\mathrm{P}_{\text {th }}$ the thermal power, $\mathrm{f}$ is mixture fraction, $\mathrm{sl}$ means standard liter (at $1013 \mathrm{hPa}$ and $273.15 \mathrm{~K}$ ), $\mathrm{T}_{\mathrm{ad}}$ is the adiabatic flame temperature, calculated for a fresh gas temperature of $298 \mathrm{~K}$ (GasEQ).

\subsection{Stereoscopic Particle Image Velocimetry}

Three-component velocity fields were measured using stereoscopic particle image velocimetry (PIV) with a repetition rate of $5 \mathrm{~Hz}$. The system (FlowMaster, LaVision) consisted of a frequency-doubled dual-head Nd:YAG laser (NewWave Solo 120), two double-shutter CCD cameras (Imager Intense, LaVision) and a programmable timing unit (PTU 9, LaVision). The laser pulse energy was $120 \mathrm{~mJ}$ at $532 \mathrm{~nm}$, and the separation time between two pulses was $11 \mu \mathrm{s}$. The laser beam was expanded to a light sheet that covered the central vertical section of the combustion chamber, with a thickness of approximately $1 \mathrm{~mm}$. The cameras were mounted on Scheimpflug adapters, and equipped with wide-angle lenses ( $\mathrm{f}=60 \mathrm{~mm}$, set to $\mathrm{f} / 2)$ and bandpass filters $(532 \pm 5 \mathrm{~nm}$ ) to reduce the influence of flame luminosity. For both cameras, the field of view covered a height from $h \approx 1$ to $h \approx 107 \mathrm{~mm}$ and a radial range from $r=-40$ to $r=39 \mathrm{~mm}$. The distance between the camera lenses and the measurement plane was $20 \mathrm{~cm}$, and the angle of view of each camera with respect to the normal of the laser sheet was $20^{\circ}$. Infrared filters were mounted between the combustor and the cameras in order to protect the cameras from thermal radiation. 
The air flow was seeded with $\mathrm{TiO}_{2}$ particles with a nominal diameter of $1 \mu \mathrm{m}$. Their relaxation time which characterizes the ability to follow the flow dynamics is $\tau \approx 5 \times 10^{-6} \mathrm{~s}$ [59]. For the condition with the highest flow rate, the maximal local velocities are $\mathrm{v} \approx 60 \mathrm{~m} / \mathrm{s}$ and the typical length scale is $1 \approx 10 \mathrm{~mm}$. The resulting Stokes number is $(\tau \cdot \mathrm{v}) / 1=0.03$, and thus velocity errors due to particle slip are considered negligible.

Velocity fields were evaluated from the particle image pairs using a commercial PIV software package (LaVision Davis 8.0). A multi-scale cross-correlation algorithm was used with a final interrogation window size of $16 \times 16$ pixel (corresponding to an in-plane spatial resolution of $1.3 \times 1.3 \mathrm{~mm}^{2}$ ) and a window overlap of $50 \%$. Based on the \pm 0.1 pixel uncertainty of the peakfinding algorithm, the random uncertainty of in-plane instantaneous velocities is $\pm 0.8 \mathrm{~m} / \mathrm{s}$. With the camera angle of $20^{\circ}$, the uncertainty of the out-of-plane velocity is about three times higher as for the in-plane uncertainty [60].

\subsection{Laser Raman scattering}

Single-shot laser Raman scattering was applied for the pointwise quantitative measurement of the major species concentrations $\left(\mathrm{O}_{2}, \mathrm{~N}_{2}, \mathrm{CH}_{4}, \mathrm{H}_{2}, \mathrm{CO}, \mathrm{CO}_{2}, \mathrm{H}_{2} \mathrm{O}\right)$ and the temperature. The measurement system has been described previously $[48,61]$ and only a short summary is given here. The radiation of a flashlamp-pumped dye laser (Candela LFDL 20, wavelength $\lambda$ $=489 \mathrm{~nm}$, pulse energy $\mathrm{E}_{\mathrm{p}} \approx 1.8 \mathrm{~J}$, pulse duration $\tau_{\mathrm{p}} \approx 3 \mu \mathrm{s}$, pulse repetition rate $5 \mathrm{~Hz}$ ) was focused into the combustion chamber and the Raman scattering emitted from the measurement volume (length $\approx 0.6 \mathrm{~mm}$, diameter $\approx 0.6 \mathrm{~mm}$ ) was collected by an achromatic lens $(\mathrm{D}=80 \mathrm{~mm}, \mathrm{f}=160 \mathrm{~mm})$ and relayed to the entrance slit of a spectrograph (SPEX 1802, $\mathrm{f}=1 \mathrm{~m}$, slit width $2 \mathrm{~mm}$, dispersion $\approx 0.5 \mathrm{~nm} / \mathrm{mm}$ ). The dispersed and spatially separated signals from the different species were detected by individual photomultiplier tubes in the focal plane of the spectrograph and sampled using boxcar integrators. The species number densities were calculated from these signals using calibration measurements and the temperature was deduced from the total number density via the ideal gas law. The simultaneous detection of all major species with each laser pulse also enabled the determination of the instantaneous mixture fraction [62]. The mixture fraction is the ratio of the mass in a sample originating from the fuel stream (here: all $\mathrm{C}$ and $\mathrm{H}$ atoms) to the total mass. The mixture fraction is a conserved scalar because it does not depend on the reaction progress.

Raman measurements typically were performed at 80 measurement locations in each flame at heights $\mathrm{h}=6,10,15,20,30,40,60$, and $80 \mathrm{~mm}$ above the burner nozzle, and at various radial locations between $\mathrm{r}=0$ and $30 \mathrm{~mm}$. Measurement locations with $\mathrm{h}<6 \mathrm{~mm}$ and $\mathrm{r}>30 \mathrm{~mm}$ were not accessible due to clipping of the solid angle of the detection optics. Four hundred single shot measurements were performed at each measurement location, yielding the joint probability density functions (PDFs) of the major species mole fractions, mixture fraction, and temperature. From the PDFs the ensemble mean and RMS values were determined. 
With respect to measurement uncertainties, it must be distinguished between systematic errors arising from, for example, uncertainties in the calibration procedure, and statistical errors which are mainly caused by the statistics (shot noise) of the detected Raman photons in a single-shot measurement. Systematic uncertainties were typically $\pm 3-4 \%$ for the temperature and mixture fraction, $\pm 3-5 \%$ for the mole fractions of $\mathrm{O}_{2}, \mathrm{H}_{2} \mathrm{O}, \mathrm{CO}_{2}$ and $\mathrm{CH}_{4}$. Because of the low concentrations of $\mathrm{H}_{2}$ and $\mathrm{CO}$ in the flames investigated, the uncertainty is relatively large for these species. It is estimated to be around $\pm 20 \%$ at a mole fraction of 0.01 . The statistical uncertainties were approximately 30\% larger than stated in a previous study [48] due to a lower pulse energy applied in the current measurements. Typical statistical uncertainties (for a single shot measurement) were $3-3.5 \%$ for the temperature and mixture fraction, $4 \%$ for $\mathrm{H}_{2} \mathrm{O}$ and $9 \%$ for $\mathrm{O}_{2}$ and $\mathrm{CO}_{2}$ in the exhaust gas. More details are given in reference [48] and a schematic drawing of the experimental setup is given in [63].

It is noted that the method of temperature measurement applied in this study (and also in other ones) is based on the total number density, which uses the signal intensities of the various Raman bands weighted by the laser pulse energy. It may happen that, during the measurement time of several hours, the signal intensity is reduced by effects like alignment drift or degradation of combustor windows. Such effects were monitored by repeated measurements in time intervals of $30-40$ minutes at the same location in the flame $(\mathrm{h}=60 \mathrm{~mm}, \mathrm{r}=0)$. If the evaluated mean temperature deviated by more than $2 \%$ from the initial value, the alignment was improved and the measurement was repeated. These influences were considered in the data evaluation procedure as well as possible, however, the remaining uncertainty could result in overestimation of the temperature because signal loss is formally equivalent to lower densities. The evaluated species concentrations were hardly affected by such effects because they were deduced from the relative signal intensities. For example, a drift in alignment usually leads to a reduction of the signals from all species without changing the ratios of the intensities. Therefore, reaction progress often is better described by the $\mathrm{H}_{2} \mathrm{O}$ mole fraction than the temperature. This has also the advantage that effects of temperature reduction due to heat loss do not affect the value of the $\mathrm{H}_{2} \mathrm{O}$ mole fraction.

\subsection{Chemiluminescence measurement}

Line-of-sight integrated imaging of $\mathrm{OH}$ chemiluminescence was performed using an intensified CMOS camera (LaVision HSS8 with HS-IRO) equipped with a Cerco UV lens $(\mathrm{f}=45 \mathrm{~mm}, \mathrm{f} / 1.8)$ and a bandpass filter $(300-325 \mathrm{~nm})$. The field of view was the whole crosssection of the combustion chamber. Depending on the operating condition, the frame rate varied between 5 and $10 \mathrm{kHz}$, and the exposure time (intensifier gate) was between 12 and 40 $\mu \mathrm{s}$.

$\mathrm{OH}$ chemiluminescence intensities from lean premixed flames are regarded as an indicator for the heat release rate $[25,64]$, but the correlation between $\mathrm{OH}$ chemiluminescence and heat release rate may be influenced by several effects like e.g. local equivalence ratio, turbulence level [65] or signal trapping [31,32]. Thus, in the current study, only qualitative information is 
derived from the chemiluminescence images, such as the variations in heat release rate and the location and extension of the flame zone. Although this technique yields line-of-sight integrated signals, spatially resolved information can be gained by deconvolution (Abel transformation), taking advantage of the rotational symmetry of the flame. This results in a "quasi 2-D image" of the center plane. Abel-transformed chemiluminenscence images often yield a better impression of the mean flame shape than the line-of-sight integrated distributions.

\section{Results and discussion}

\subsection{Flame shape from chemiluminescence distributions}

The mean $\mathrm{OH}$ chemiluminescence distributions from the three flames, displayed in Fig.2, show that the flame shapes are very similar, extending to a height of $\mathrm{h} \approx 55 \mathrm{~mm}$ with the majority of the heat release between $\mathrm{h}=25$ and $45 \mathrm{~mm}$. The measurements have been performed with identical detector settings for the 3 flames so that the intensities can be compared. While the flames at $\varphi=0.9$ have very similar intensity levels, the flame at $\varphi=0.8$ exhibits lower intensities. This is explained by the lower adiabatic flame temperature [7]. The Abel-transformed chemiluminescence distributions, shown in the right column represent a quasi two-dimensional vertical cut through the mean line-of-sight integrated distribution of the left column. The spots of increased intensity near the flame axis and the light stripe pattern are artifacts of the Abel transformation.

It is seen that the flames have a conical shape and that the flame anchoring region is below $\mathrm{h}$ $=0$. From the visual impression, flame anchoring appears close to the central bluff body and no combustion takes place in the immediate vicinity of the flame axis. A comparison with the mean flow field from Fig.3 reveals that the flame zone resides in the inner shear layer. No combustion takes place in the outer shear layer, as is sometimes the case in gas turbine flames. With respect to the comparison between the flames PP09 and TP09, a closer inspection reveals that the perfectly premixed flame exhibits a higher chemiluminescence intensity at the nozzle exit, which is indicative of a better flame stabilization. It is noted that this result is hardly affected by effects of signal trapping, because $\mathrm{OH}$ concentrations are relatively small in this region [48]. The inspection of instantaneous $\mathrm{OH}$ chemiluminescence images (not displayed) confirms that flame PP09 is - on the average - better anchored than TP09. In flame TP09 the reaction zone is more frequently lifted from the nozzle than in flame PP09. This can be explained by the occurrence of very fuel-lean or fuel-rich mixtures in flame TP09 (see the following paragraph). A close look also shows the flame zone of the technically premixed flame is slightly larger than that of the perfectly premixed flames.

\subsection{Flow field}


The mean flow field of the flame PP08 is shown in Fig.3. The arrows represent the flow directions in the imaged plane and the colors indicate the magnitude of the velocity including all three velocity components. The flow field is typical of swirling flows: The inflowing jet is conically shaped, there are an inner and outer recirculation zones (IRZ and ORZ, respectively), and corresponding shear layers exist between the inflow and the recirculating flows. It is noted that instantaneous flow field structures differ drastically from the mean shape, in that they exhibit numerous vortices of different sizes, mainly located in the shear layers [66]. The shapes of the flow fields for the other flames are very similar, with the most significant difference being higher velocities in flame PP08 because of the higher air mass flow rate (see Table 1).

Radial profiles of the mean values of all three velocity components are shown in Fig. 4 for $\mathrm{h}=$ $6 \mathrm{~mm}$. The profiles span a radial range from $\mathrm{r}=-40 \mathrm{~mm}$ to $39 \mathrm{~mm}$, the remainder of the flow field up to $\mathrm{r}=43 \mathrm{~mm}$ is obscured by the posts of the combustion chamber. At $\mathrm{h}=6 \mathrm{~mm}$ (and also at $\mathrm{h}=10 \mathrm{~mm}$ ), the axial velocity is positive in the ORZ up to $\mathrm{r}=40 \mathrm{~mm}$, but the recirculation is seen in the radial velocity component which is directed towards the axis in this region.

Besides the higher axial velocity of flame PP08, differences are observed in the IRZ where the perfectly premixed flame exhibits a slower reflow than the technically premixed one. More differences become obvious when the radial profiles of the different velocity components are compared at other downstream locations as shown in Fig.5 for $\mathrm{h}=20$ and 40 $\mathrm{mm}$. A closer look shows that the profiles of the perfectly premixed flame are shifted slightly further outwards compared to the technically premixed one. Although the amount is small $(<$ $1 \mathrm{~mm}$ ) it is seen consistently in the profiles. The shift is also apparent in the radial profiles of species distributions presented below. The reason for the shift has not been finally clarified, but there are 2 obvious differences between the flames that might contribute to it. One is the difference in flame stabilization observed in the chemiluminescence images (see 3.1). The steadier combustion at the nozzle exit of the perfectly premixed flame may lead to a slightly higher thermal expansion and thus a larger radial shift than in the technically premixed flame. It is also conjectured that the reason for the difference lies in the injection of the fuel into the swirler for the technically premixed flame. The flow field in the swirler could not be measured, however, Fig.7 of reference [52] gives an impression of the (numerically simulated) methane jets within the swirler vanes. Obviously the methane jets change the flow field in the swirler and presumably the change has an influence of the flow field within the combustion chamber. The shift in the radial profiles between TP09 and PP09 implies a change in the swirl number, which in turn is associated with a change in the size and strength of the inner recirculation zone. The interaction of the methane jet and the air flow in the swirler vanes is hardly possible to investigate experimentally. However, it would be interesting to see whether a numerical simulation can identify the cause of effects.

\subsection{Temperature and species distributions and mixing and reaction progress}


The flames exhibit significant effects of turbulence-chemistry interaction. This is demonstrated by the scatterplot in Fig.6, which shows the correlation between temperature and mixture fraction for flame PP08 at $\mathrm{h}=6 \mathrm{~mm}$. Each dot represents the result of a single shot Raman measurement and the results from different radial locations are marked by different colors. In comparison, the solid line displays the thermo-chemical state at adiabatic equilibrium, and the vertical dashed line indicates the global mixture fraction that corresponds to $\varphi=0.8$. The scatter in mixture fraction is caused by the statistical measurement uncertainty (shot noise with standard deviation of typically $3-3.5 \%$ ). The slight drift of the mixture fraction distribution at low temperatures to smaller values is due to a systematic inaccuracy of the Raman measurement.

It is seen that the temperatures vary between room temperature and $\mathrm{T}_{\mathrm{ad}}$ and that most samples deviate drastically from adiabatic equilibrium. Such behavior has often been observed in flames with recirculating burned gas $[38,40,61,67-70]$. The samples with room temperature originate from the inflowing cold jet, whereas the samples with intermediate temperatures are predominantly from the shear layers. The latter samples are mixtures of fuel, air, and exhaust gas that can be explained either by mixtures of gas from the recirculation zones with fresh gas that has not yet reacted due to ignition delay, or by local flame extinction that leaves a fluid pocket in a partially reacted mixture [68].

It is noted that spatial averaging effects of the Raman measurement may also lead to apparent intermediate temperatures, while in reality hot exhaust gas and cold fresh gas are present in different parts of the measurement volume. Considering the probe size of approximately 0.6 $\mathrm{mm}$ in all three dimensions, significant spatial averaging is only expected if a steep gradient lies within the probe volume. Such large gradients are almost exclusively restricted to the reaction zone. In a previous study in this burner planar laser induced fluorescence (PLIF) of $\mathrm{OH}$ was applied at a slightly different operating condition $\left(\varphi=0.83, \mathrm{P}_{\mathrm{th}}=30 \mathrm{~kW}\right)$ [48]. Large gradients of $\mathrm{OH}$ which most likely represented reaction zones were found in the inner shear layer. At $\mathrm{h}=6 \mathrm{~mm}$, they occurred in the radial region $\mathrm{r} \approx 6-14 \mathrm{~mm}$. A rough estimation yielded that the probability of finding a reaction zone within the probe volume in this radial region was around $7.5 \%$, very similar to a value estimated for another GT model combustor [68]. In comparison, the fraction of samples with intermediate temperature at $\mathrm{h}=6 \mathrm{~mm}, \mathrm{r}=$ $10 \mathrm{~mm}$ is larger than $50 \%$. Thus, spatial averaging effects cannot be excluded but contributed only to a small extent to the observed number of samples with intermediate temperature. Further, many of those samples originated from the outer shear layer $(\mathrm{r}=17-18 \mathrm{~mm})$ where gradients were small and spatial averaging effects are expected to be insignificant.

More details of the thermochemical state can be seen from the correlation between $\mathrm{H}_{2} \mathrm{O}$ mole fraction and temperature displayed in Fig. 7 for the same height. The samples with the highest temperatures (close to $\mathrm{T}_{\mathrm{ad}}$ ) were measured in the inner recirculation zone. Most of these samples are expected to have experienced a relatively long residence time at high temperatures due to the recirculation and have hardly been in contact with the combustor housing. Thus, it is not surprising that these samples are completely reacted and close to 
adiabatic equilibrium. The samples from the outer recirculation zone exhibit almost the same water content, but at significantly lower temperatures. The temperature loss is explained by the contact of the gas with the combustor walls during the recirculation loop. Thus, these samples are (nearly) at chemical equilibrium, which is confirmed by the other major species mole fractions that are not displayed here, but their temperature is reduced compared to $T_{a d}$. All the samples with intermediate temperatures are well explained by pure mixing of cold fuel/air mixtures (with $\mathrm{X}_{\mathrm{H} 2 \mathrm{O}}=0$ ) and the gas from the recirculation zones. The mixtures with gas from the IRZ are located in the inner shear layer (ISL, $r \approx 10-12 \mathrm{~mm}$ ) and the mixtures with gas from the ORZ are located in the outer shear layer (OSL, $r \approx 17-18 \mathrm{~mm}$ ). As will be discussed below, the number of samples with low and intermediate temperatures decreases with downstream location until all fuel is consumed at $\mathrm{h} \approx 50 \mathrm{~mm}$.

The mean temperatures and mole fractions presented below are Reynolds (ensemble) averages, typically over 400 laser shots at each location. Fig.8 shows the mean temperature distribution for flame PP08. The values from the discreet measurement locations have been interpolated to yield a quasi 2D distribution. The increase in temperature reflects the mean progress in burnout. The temperature difference between the IRZ and ORZ is almost $300 \mathrm{~K}$ and, as discussed above, reflects the temperature reduction due to heat loss at the walls. It is seen that the regions with temperature gradients (flame zone) extend beyond $\mathrm{r}=30 \mathrm{~mm}$, the limit of the optically accessible range for the Raman measurements.

For the comparison of the perfectly and technically premixed flames, differences in the degree of mixing are of major interest. Fig. 9 shows scatterplots of temperature versus mixture fraction at $\mathrm{h}=6 \mathrm{~mm}$ for flames PP09 and TP09. The dots and lines have the same meaning as in Fig. 6 and, in addition, the stoichiometric mixture fraction is indicated. The apparent temperatures significantly higher than the adiabatic flame temperature for PP09 are not realistic, and are explained by signal loss as previously described. With respect to variation in mixture fraction, flame PP09 shows the expected behavior, i.e. a scatter around $f_{\text {global }}$ that corresponds to the measurement system inherent fluctuations. In contrast, flame TP09 exhibits variations that reach from $\mathrm{f} \approx 0.03$ to $\mathrm{f} \approx 0.07$ (corresponding to $\varphi \approx 0.53$ to $\varphi \approx 1.29$ ). For a more precise quantification of the differences in scatter, the fresh gas mixtures in the radial region of the inflow $(\mathrm{r}=13-16 \mathrm{~mm})$ were evaluated. To exclude contributions from recirculated burned gas the analysis was restricted to samples with $\mathrm{T}<400 \mathrm{~K}$. For the flame PP09 the standard deviation of the mixture fraction was $3.12 \%$, for the flame TP09 it was $18.7 \%$. In comparison, the measurement precision for the mixture fraction was $3-3.5 \%$. Thus, the measured standard deviation for the flame PP09 was predominantly caused by the measurement precision. Similar variations have been observed before in this burner at another operating condition [48]. The deviations from $f_{\text {global }}$ are reduced with increasing downstream location, as shown for example in the scatterplots of $\mathrm{H}_{2} \mathrm{O}$ mole fraction versus mixture fraction in Fig. 10 at $\mathrm{h}=30 \mathrm{~mm}$. However, considering that flame reactions begin below $\mathrm{h}=0$ (see Fig.2), flame TP09 clearly burns to a considerable extent at conditions with $\varphi \neq 0.9$, which has significant consequences for the combustion chemistry and flame anchoring. 
Next, the reaction progress of the flames PP09 and TP09 is compared based on the mean mole fractions of $\mathrm{H}_{2} \mathrm{O}$. Here, a reaction progress variable is defined as $\mathrm{c}=\mathrm{X}_{\mathrm{H} 2 \mathrm{O}} / \mathrm{X}_{\mathrm{H} 2 \mathrm{Ofinal}}$ where $\mathrm{X}_{\mathrm{H} 2 \mathrm{Ofinal}}$ is the mean water mole fraction determined at the largest measurement height $(\mathrm{h}=80$ $\mathrm{mm}$ ) where burnout has long been completed. In Fig.112D plots of c are presented, which have been generated by interpolation in the same manner as in Fig.8. The somewhat angular shape of the distributions is caused by the interpolation procedure, in which no smoothing was applied. The distributions reflect the conical shape of the flames and reveal only minor differences in the reaction progress. The apparent differences seen in the IRZ and ORZ are predominantly an effect of the steps in the color scale and are smaller in number than they appear.

The scatterplots of $\mathrm{H}_{2} \mathrm{O}$ versus mixture fraction at $\mathrm{h}=30 \mathrm{~mm}$ shown in Fig. 10 confirm this result. Although they bear a slight indication that the technically premixed flame might be a bit ahead in water production, and thus reaction progress. This is supported by Fig.12, which shows radial profiles of the water mole fraction at selected heights for the two flames. Once again, there are only vague indications that the flame TP09 is burning faster. However, the profiles do not match exactly in radial position, with those for PP09 shifted radially outwards by approximately $1 \mathrm{~mm}$ (at $\mathrm{h}=15 \mathrm{~mm}$ ) relative to TP09. This deviation is larger than the measurement uncertainty and was confirmed in a repeated measurement. This trend also was observed in the velocity profiles, and it was conjectured that it is associated with the difference in flame anchoring or with the influence of the fuel injection into the air flow within the swirler vanes.

The concentrations of $\mathrm{CO}$ are sensitive to the equivalence ratio and finite rate chemistry effects, and therefore are a good indicator of differences between flames. However, CO is difficult to measure by Raman scattering in flames because of its low concentrations and the cross talk of the CO Raman band with that of $\mathrm{N}_{2}$, which is generally more intense due to the large $\mathrm{N}_{2}$ concentrations in air-fed combustion [71]. Thus, the results presented below are indicative of qualitative trends, but quantitative interpretation is subject to relatively large uncertainty.

Figure13 shows a scatterplot of $\mathrm{CO}$ mole fraction versus temperature at $\mathrm{h}=6 \mathrm{~mm}$ for flame PP09. Single shot mole fractions up to $\mathrm{X}_{\mathrm{CO}}=0.04$ are observed. In comparison, the adiabatic equilibrium value for $\varphi=0.9$ is $\mathrm{X}_{\mathrm{CO}}=0.00235$. The distribution exhibits a broad maximum at temperatures around $1200-1600 \mathrm{~K}$, and these samples predominantly stem from the inner shear layer where hot combustion products from the IRZ mix with fresh fuel/air mixtures from the inflowing jet. For the further analysis and comparison, conditional mean values are examined. The single-shot results were sorted with respect to temperature and, within temperature intervals of $50 \mathrm{~K}$, the mole fractions were averaged. This procedure reduces the influence of single-shot scatter and yields a clearer representation. In Fig. 14 conditionally averaged $\mathrm{CO}$ mole fractions are displayed for all three flames at $\mathrm{h}=6$ and $10 \mathrm{~mm}$. Clearly, the flame TP09 has the largest CO concentrations. This is not surprising because the fuel-rich mixtures occurring in this flame (Fig.9) contribute disproportionately to CO production. The 
perfectly premixed flames at $\varphi=0.8$ and 0.9 exhibit comparable CO levels. At chemical equilibrium, a flame with $\varphi=0.9$ is expected to have higher $\mathrm{CO}$ levels than a flame with $\varphi=$ 0.8 . However, it is clear that the flames considered here are not at chemical equilibrium and that effects of turbulence-chemistry interaction influence the $\mathrm{CO}$ level. Also, the differences between PP08 and PP09 seen in Fig.14 are too small relative to the measurement uncertainty to draw definite conclusions. Finally, in Fig.15 radial profiles of mean $\mathrm{CO}$ mole fractions at different downstream locations are examined for the flames with $\varphi=0.9$. The offset on the order of $\mathrm{X}_{\mathrm{CO}}=0.002$ observed in the technically premixed flame is obviously not realistic and due to an incorrect crosstalk correction. Once again, the technically premixed flame clearly has higher $\mathrm{CO}$ levels than the perfectly premixed flames, even if the offset is subtracted. The peaks of the mean $\mathrm{CO}$ mole fraction move radially outwards with increasing downstream location in the same way as the inner shear layer. Large mean CO mole fractions are seen up to $\mathrm{h} \approx 40 \mathrm{~mm}$; for $\mathrm{h}>40 \mathrm{~mm}$ the shear layer moves out of the Raman observation field.

\section{Summary and conclusions}

A gas turbine model combustor for premixed swirl flames has been operated with methane/air flames at atmospheric conditions. The main subject of the study has been the characterization of the influence of the method of premixing on the combustion process using chemiluminescence imaging, stereoscopic particle image velocimetry and single-shot laser Raman scattering. Three flames of identical thermal power have been studied, two with perfect premixing and different equivalence ratio and one with technical premixing. Previous measurements of thermo-acoustic instabilities in this burner revealed that perfectly premixed flames exhibited a significantly lower noise level than technically premixed flames. To investigate effects of premixing on the physics and chemistry of combustion without the complicating effects of combustion instabilities, the flames chosen were "quiet" and without coherent helical flow structures.

The overall features of the flames investigated did not change drastically with premixing mode or change of the equivalence ratio. They were characterized by the typical flow field of confined swirl flames and pronounced effects of turbulence-chemistry interactions. However, a closer look revealed notable differences. The shape of the flow field and species distributions was slightly different. Compared to the perfectly premixed flame, the technically premixed flame exhibited an unsteadier flame anchoring at the nozzle exit in the shear layer between the inflowing jet and the inner recirculation zone. This was attributed to effects of unmixedness and the occurrence of lean mixtures unfavorable for flame stabilization. The radial profiles of the velocity and species were located slightly further outside for the perfectly premixed flame in comparison to the technically premixed flame. It could not be clarified whether the differences in flame anchoring were responsible for this or the influence of the fuel jets that were injected into the air flow within the swirler vanes. The degree of unmixedness of the technically premixed flame was characterized by the mixture fraction measurements and revealed a significant scatter from very lean to rich mixtures. While the 
mean reaction progress, quantified via the water mole fractions, was hardly affected by this, the $\mathrm{CO}$ concentrations reflected a significant influence. The higher $\mathrm{CO}$ concentration level observed in the partially premixed flame is explained by the occurrence of mixtures with $\varphi>$ 0.9 .

Beyond the quantification of the differences in combustion behavior, the new experimental results expand the data archive available for this combustor and enable a better comparison of numerical and experimental results.

\section{Acknowledgements}

The financial support by the German Research Council (DFG) within the Collaborative Research Center 606 is gratefully acknowledged. We furthermore like to thank Prof. Henning Bockhorn for his extraordinary merits and achievements in the Collaborative Research Center 606.

\section{References}

[1] A.H. Lefebvre, Gas Turbine Combustion, Taylor \& Francis, Philadelphia (1999).

[2] S.M. Correa, Proc. Combust. Inst. 27 (1998) 1793.

[3] J.J. Keller, AIAA J. 33 (1995) 2280.

[4] E.C. Fernandes, M.V. Heitor, Unsteady Flames and the Rayleigh Criterion, in Unsteady Combustion, Eds. F. Culick, M.V. Heitor, J.H. Whitelaw, Kluwer Academic press, Dordrecht, 1996, p.1.

[5] C.O. Paschereit, E. Gutmark, W. Weisenstein, Combust. Sci. Technol. 138 (1998) 213.

[6] S. Candel, Proc. Combust. Inst. 29 (2002) 1.

[7] J.G. Lee, D.A. Santavicca, J. Propulsion and Power 19 (2003) 735.

[8] T.C. Lieuwen, V. Yang (Eds.), Combustion Instabilities in Gas Turbine Engines: Operational Experience, Fundamental Mechanisms, and Modeling, American Institute of Aeronautics and Astronautics, Inc., Reston, Virginia (2006).

[9] Y. Huang, V. Yang, Prog. Energy Combust. Sci. 35 (2009) 293.

[10] T.C. Lieuwen, V. Yang (Eds.), Gas Turbine Emissions, Cambridge, University Press, New York (2013).

[11] K.J. Syed, E. Buchanan, Proc. of ASME Turbo Expo (2005) GT-2005-68070.

[12] Th. Sattelmayer, J. Eng. Gas Turbines Power 125 (2003) 11.

[13] B. Schürmans, V. Bellucci, F. Güthe, F. Meili, P. Flohr, C.O. Paschereit, Proc. of ASME Turbo (2004) GT2004-53831.

[14] N. Syred, Prog. Energy Combust. Sci. 32 (2006) 93.

[15] M. Stöhr, R. Sadanandan, W. Meier, Proc. Combust. Inst. 32 (2009) 2925. 
[16] A.M. Steinberg, I. Boxx, M. Stöhr, C.D. Carter, W. Meier, Combust. Flame 157 (2010) 2250 .

[17] V. Caux-Brisebois, A.M. Steinberg, C.M. Arndt, W. Meier, Combust. Flame 161 (2014) 3166.

[18] H. Li, S. Wehe, K. McManus, 45th AIAA/ASME/SAE/ASEE Joint Propulsion Conference \& Exhibit, AIAA 2009-5522.

[19] J. Ballester, T. García-Armingol, Prog. Energy Combust. Sci. 36 (2010) 375.

[20] M.C. Thurber, R.K. Hanson, Exp. Fluids 30 (2001) 93.

[21] C. Schulz, V. Sick, Prog. Energy Combust. Sci. 31 (2005) 75.

[22] O. Dégardin, B. Renou, A.M. Boukhalfa, Exp. Fluids 40 (2006) 452.

[23] M. Stöhr, C. M. Arndt, W. Meier, Proc. Combust. Inst. 35 (2015) in print; doi: 10.1016/j.proci.2014.06.95.

[24] V.N. Nori, J.M. Seitzman, AIAA 2007-466. 45 ${ }^{\text {th }}$ AIAA Aerospace Science Meeting and Exhibition, 8-11 January 2007, Reno, Nevada.

[25] Y. Hardalupas, C.S. Panoutsos, A.M.K.P. Taylor, Exp. Fluids 49 (2010) 883.

[26] F. Guethe, D. Guyot, G. Singla, N. Noiray, B. Schuermans, Appl. Phys. B 107 (2012) 619.

[27] M.L. Greene, V. Sick, Appl. Phys. B 113 (2013) 87.

[28] N.A. Worth, J.R. Dawson, Meas. Sci. Technol. 24 (2013) 024013.

[29] N.B. Anikin, R. Suntz, H. Bockhorn, Chemie Ingenieur Technik 85 (2013) 696.

[30] J. Floyd, A.M. Kempf, Proc. Combust. Inst. 33 (2011) 751.

[31] R. Sadanandan, W. Meier, J. Heinze, Appl. Phys. B 106 (2012) 717.

[32] A. Brockhinke, J. Krüger, M. Heusing, M. Letzgus, Appl. Phys B 107 (2012) 539.

[33] N. Ebersohl, Th. Klos, R. Suntz, H. Bockhorn, Proc. Combust. Inst. 27 (1998) 997.

[34] A. Brockhinke, S. Haufe, K. Kohse-Höinghaus, Combust. Flame 121 (2000) 367.

[35] R.S. Barlow, C.D. Carter, R.W. Pitz, in K. Kohse-Höinghaus, J. Jeffries, Eds., Applied Combustion Diagnostics, Taylor \& Francis, New York 2002.

[36] K. Kohse-Höinghaus, R.S. Barlow, M. Aldén, J. Wolfrum, Proc. Combust. Inst. 30 (2005) 89.

[37] R.S. Barlow, Proc. Combust. Inst. 31 (2007) 49.

[38] M.A. Gregor, F. Seffrin, F. Fuest, D. Geyer, A. Dreizler, Proc. Combust. Inst. 33 (2009) 1732.

[39] U. Stopper, M. Aigner, H. Ax, W. Meier, R. Sadanandan, M. Stöhr, A. Bonaldo, Exp. Thermal Fluid Science 34 (2010) 396.

[40] J. Kojima, D.G. Fischer, Combust. Sci. Technol. 185 (2013) 1735. 
[41] A.C. Eckbreth, Laser Diagnostic for Combustion Temperature and Species, Gordon and Breach, The Netherlands, 1996

[42] A.R. Masri, R.W. Dibble, R.S. Barlow, Prog. Energy Combust. Sci. 22 (1996) 307.

[43] H. Ax, U. Stopper, W. Meier, M. Aigner, F. Güthe, J. Eng. Gas Turbines Power 132 (2010) 051503.

[44] R. Lückerath, O. Lammel, M. Stöhr, I. Boxx, U. Stopper, W. Meier, B. Janus, B. Wegner, Proc. of 2011 ASME Turbo Expo, GT2011-45790.

[45] U. Stopper, W. Meier, R. Sadanandan, M. Stöhr, M. Aigner, G. Bulat, Combust. Flame 160 (2013) 2103.

[46] G. Lartigue, U. Meier, C. Bérat, Appl. Thermal Eng. 24 (2004) 1583-1592.

[47] S. Roux, G. Lartigue, T. Poinsot, U. Meier, C. Bérat, Combust. Flame 141 (2005) 40.

[48] W. Meier, P. Weigand, X.R. Duan, R. Giezendanner-Thoben, Combust. Flame 150 (2007) 2.

[49] J. Galpin, A. Naudin, L. Vervisch, C. Angelberger, O. Colin, P. Domingo, Combust. Flame 155 (2008) 247.

[50] B. Fiorina, R. Vicquelin, A. Auzillon, N. Darabiha, O. Gicquel, D. Veynante, Combust. Flame 157 (2010) 465.

[51] G. Lecocq, S. Richard, O. Colin, L. Vervisch, Combust. Flame 158 (2011) 1201.

[52] B. Franzelli, E. Riber, L. Y. M. Gicquel, T. Poinsot, Combust. Flame 159 (2012) 621.

[53] L.Y.M. Gicquel, G. Staffelbach, T. Poinsot, Prog. Energy Combust. Sci. 38 (2012) 782.

[54] J.-M. Lourier, B. Noll, M. Aigner, Proc. of ASME Turbo Expo 2014, GT2014-26200.

[55] I. Boxx, C. Arndt, C.D. Carter, W. Meier, Exp. Fluids 52 (2012) 555.

[56] A.M. Steinberg, C.M. Arndt, W. Meier, Proc. Combust. Inst. 34 (2013) 3117.

[57] K. Oberleithner, M. Stöhr, S.H. Im, C.M. Arndt, A.M. Steinberg, Combust. Flame, submitted

[58] B. Janus, A. Dreizler, J. Janicka, Flow, Turbul. Combust. 75 (2005) 293.

[59] M. Raffel, C.E. Willert, S.T. Wereley, J. Kompenhans, Particle Image Velocimetry, Springer, Berlin (2007).

[60] N. J. Lawson, J. Wu, Meas. Sci. Technol. 8 (1997) 1455.

[61] O. Keck, W. Meier, W. Stricker, M. Aigner, Combust. Sci. Technol. 174 (2002) 117.

[62] V. Bergmann, W. Meier, D. Wolff, W. Stricker, Appl. Phys. B 66 (1998) 489.

[63] X.R. Duan, W. Meier, P. Weigand, B. Lehmann, Appl. Phys. B 80 (2005) 389.

[64] L.C. Haber, U. Vandsburger, Combust. Sci. Technol. 175 (2003) 1859.

[65] B.O. Ayoola, R. Balachandran, J.H. Frank, E. Mastorakos, C.F. Kaminski, Combust. Flame 144 (2006)1. 
[66] W. Meier, I. Boxx, M. Stöhr, C.D. Carter, Exp. Fluids 49 (2010) 865.

[67] A.R. Masri, P.A.M. Kalt, R.S. Barlow, Combust. Flame 137 (2004) 1.

[68] W. Meier, X.R. Duan, P. Weigand, Combust. Flame 144 (2006) 225.

[69] L. Wehr, W. Meier, P. Kutne, C. Hassa, Proc. Combust. Inst. 31 (2007) 3099.

[70] M.S. Sweeney, S. Hochgreb, M.J. Dunn, R.S. Barlow, Combust. Flame 159 (2012) 2912.

[71] W. Meier, R.S. Barlow, Y.-L. Chen, J.-Y. Chen, Combust. Flame 123 (2000) 326. 


\section{Figure Captions}

Fig.1: Schematic drawing of the gas turbine model combustor and photo of a typical flame.

Fig.2: Mean chemiluminescence distributions of the flames PP08 (upper) row, PP09 (middle row) and TP09 (lower row). The left column shows the line-of-sight integrated chemiluminescence intensity distribution, the right column the Abel-transformed "cut" through the flame.

Fig.3: Averaged flow field of the flame PP08. The arrows indicate the flow direction and the colors represent the magnitude of the total velocity including all 3 components.

Fig.4: Radial profiles of the mean values of all three velocity components at $\mathrm{h}=6 \mathrm{~mm}$.

Fig.5: Radial profiles of the mean values of the axial, radial and tangential velocities at $h=20$ and $40 \mathrm{~mm}$. Compared are the velocities of the technically and perfectly premixed flames.

Fig.6: Correlation (scatterplot) between temperature and mixture fraction for flame PP08 at $h$ $=6 \mathrm{~mm}$. Each dot is the result of a single shot measurement and the solid curve shows the correlation at adiabatic equilibrium. Different radial regions are distinguished by different colors. $f_{\text {glob }}$ indicates the global mixture fraction as derived from the flow meters.

Fig.7: Scatterplot of $\mathrm{H}_{2} \mathrm{O}$ mole fraction vs. temperature for flame PP08 at $\mathrm{h}=6 \mathrm{~mm}$. IRZ and ORZ mean inner and outer recirculation zone, respectively. ISL is inner shear layer, OSL outer shear layer. The cross marks the state of adiabatic equilibrium.

Fig.8: 2D plot of the mean temperature distribution of flame PP08 generated by interpolation between the measurement points.

Fig.9: Scatterplot of temperature vs. mixture fraction at $\mathrm{h}=6 \mathrm{~mm}$ for the flames PP09 (upper frame) and TP09 (lower frame).

Fig. 10: Scatterplots of $\mathrm{H}_{2} \mathrm{O}$ mole fraction vs. mixture fraction at $\mathrm{h}=30 \mathrm{~mm}$ for the flames PP09 and TP09.

Fig.11: 2D plots of mean reaction progress of the flames PP09 and TP09 generated by interpolation between the measurement locations.

Fig.12: Radial profiles of the mean $\mathrm{H}_{2} \mathrm{O}$ mole fractions of the flames PP09 and TP09 at different heights.

Fig.13: Scatterplot of $\mathrm{CO}$ mole fraction vs temperature at $\mathrm{h}=6 \mathrm{~mm}$ for the flame PP09. The largest $\mathrm{CO}$ concentrations are present in the inner shear layer (ISL).

Fig.14: Conditionally averaged $\mathrm{CO}$ mole fractions at $\mathrm{h}=6$ and $10 \mathrm{~mm}$ for the flames with $\varphi=$ 0.9 .

Fig.15: Radial profiles of the mean CO mole fractions recorded at different heights. 
Fig.1: Schematic drawing of the gas turbine model combustor and photo of a typical flame.

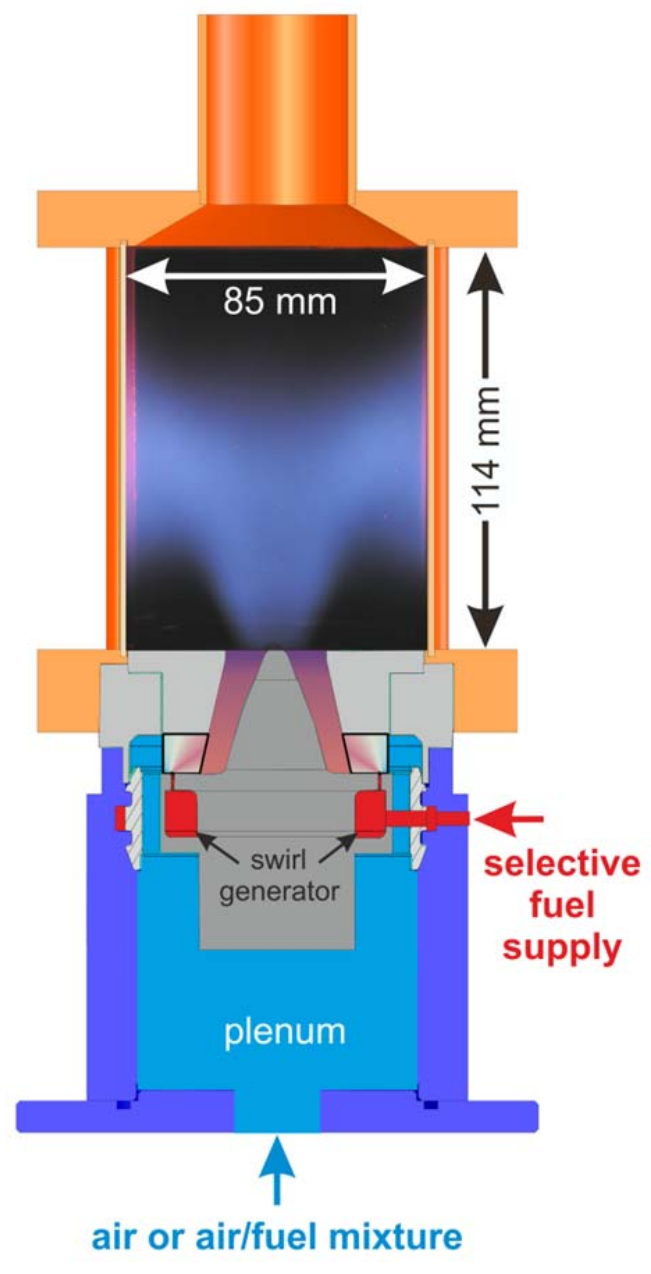


Fig.2: Mean chemiluminescence distributions of the flames PP08 (upper row), PP09 (middle row) and TP09 (lower row). The left column shows the line-of-sight integrated chemiluminescence intensity distribution, the right column the Abel-transformed "cut" through the flame.

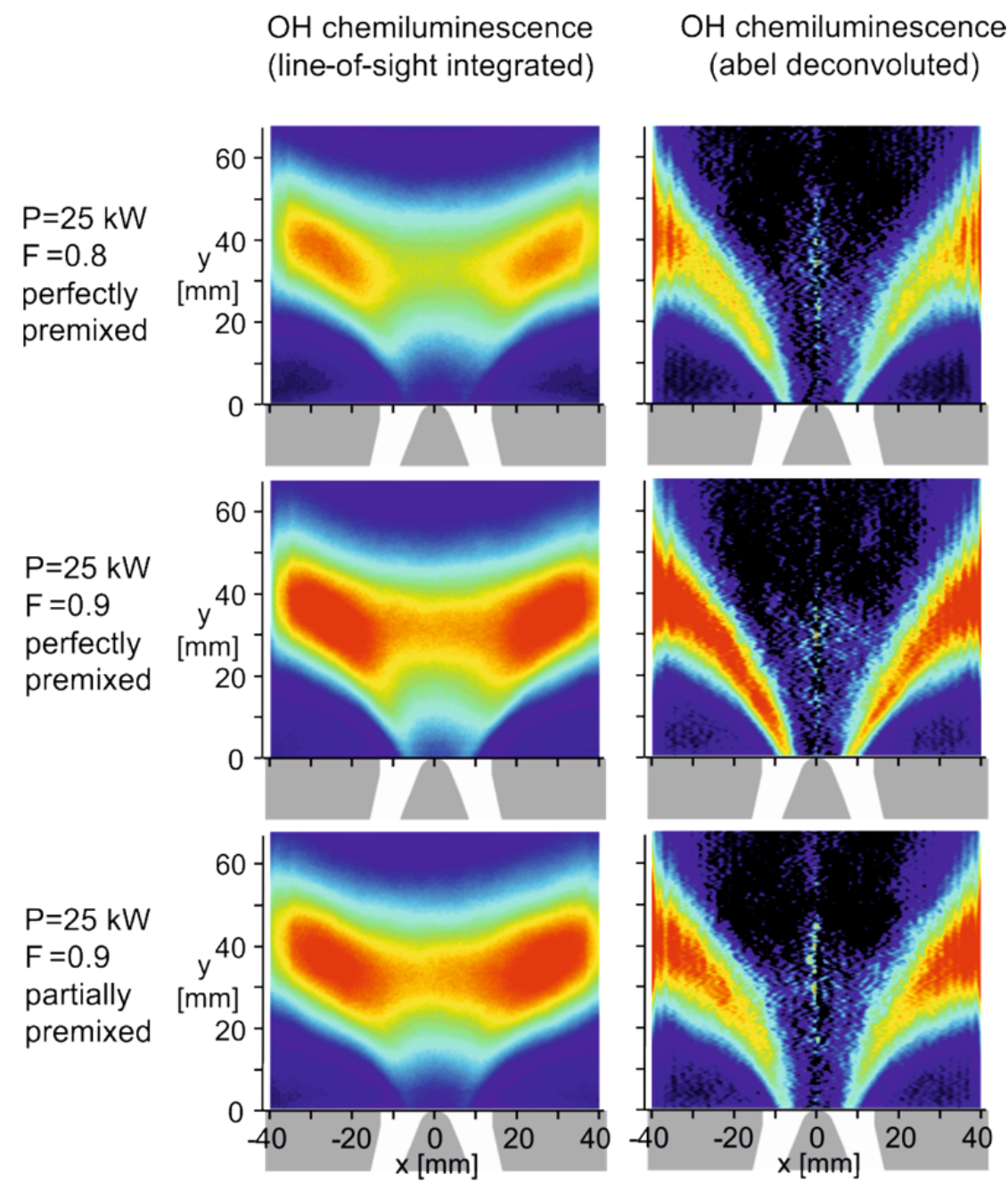


Fig.3: Averaged flow field of the flame PP08. The arrows indicate the flow direction and the colors represent the magnitude of the total velocity including all 3 components.

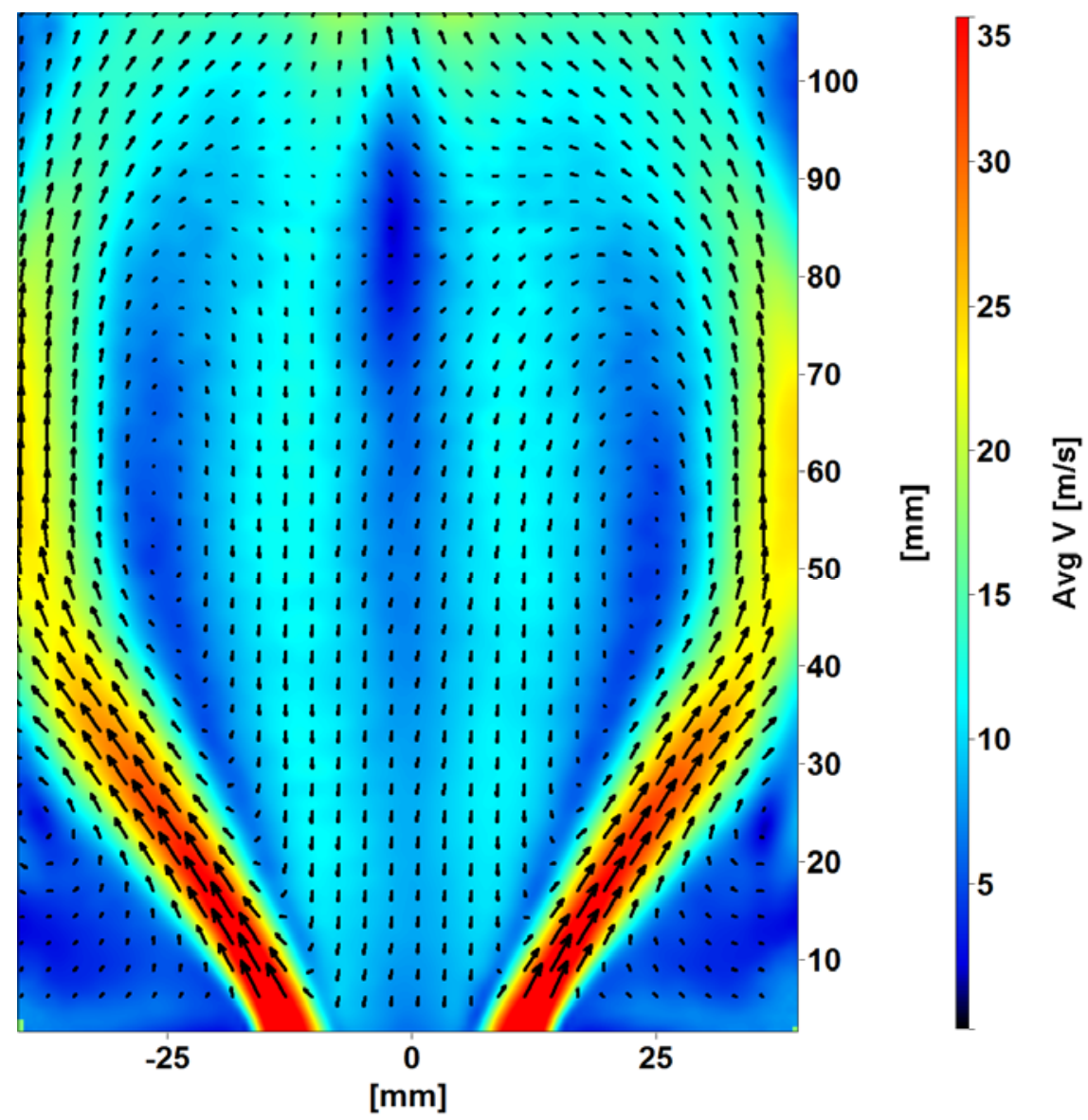


Fig.4: Radial profiles of the mean values of all three velocity components at $\mathrm{h}=6 \mathrm{~mm}$.
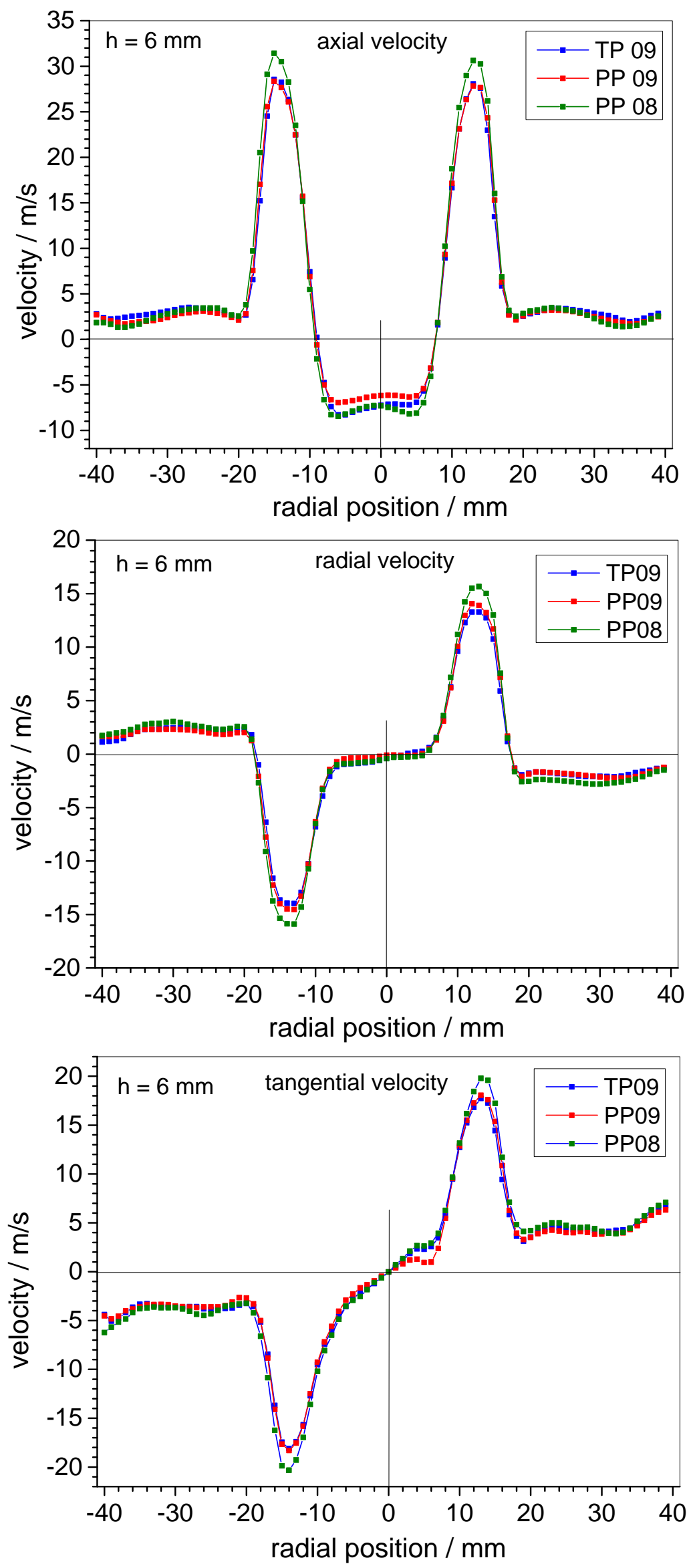
Fig.5: Radial profiles of the mean values of the axial, radial and tangential velocities at $\mathrm{h}=20$ and $40 \mathrm{~mm}$. Compared are the velocities of the technically and perfectly premixed flames.
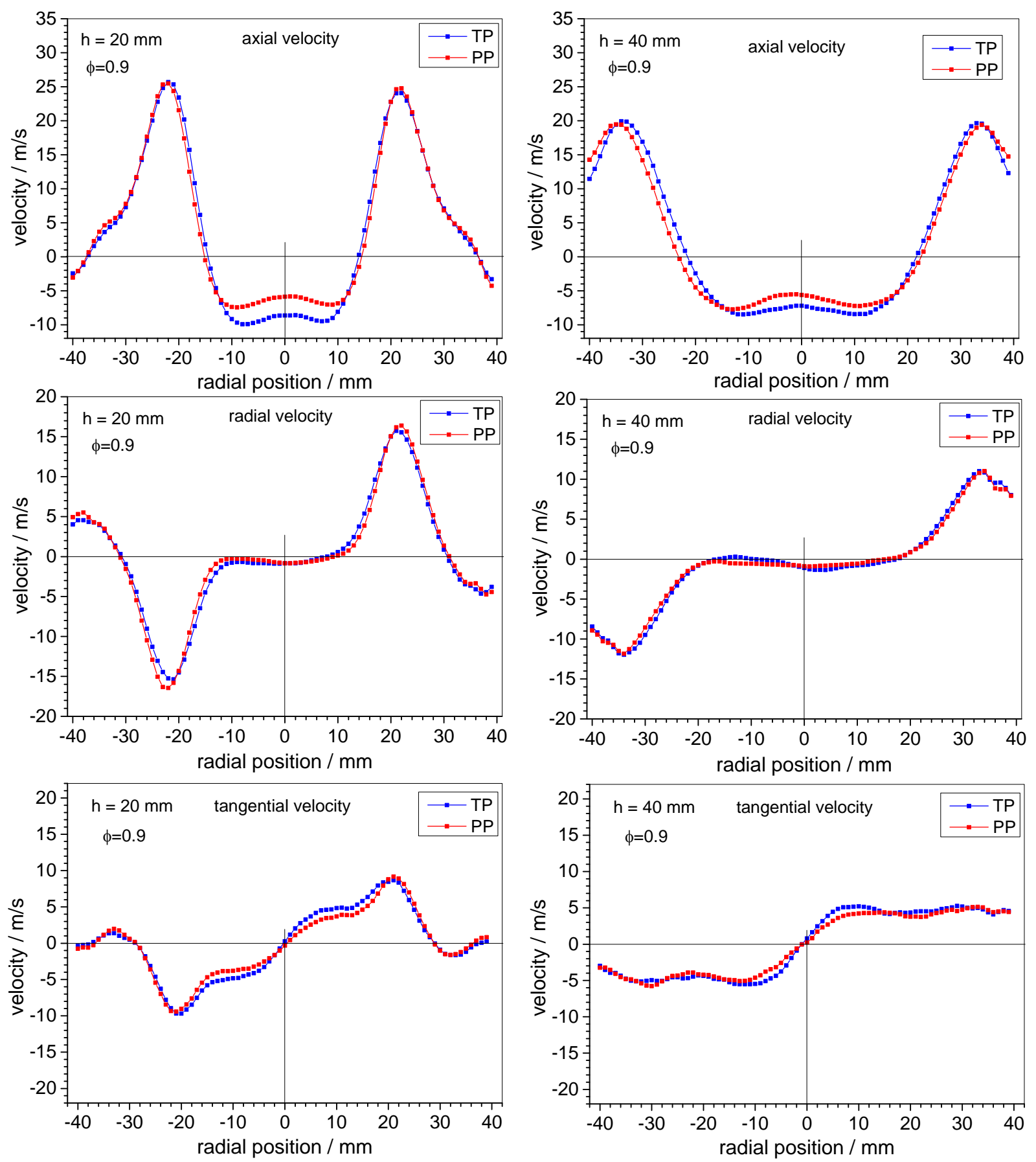
Fig.6: Correlation (scatterplot) between temperature and mixture fraction for flame PP08 at $\mathrm{h}$ $=6 \mathrm{~mm}$. Each dot is the result of a single shot measurement and the solid curve shows the correlation at adiabatic equilibrium. Different radial regions are distinguished by different colors. $f_{\text {glob }}$ indicates the global mixture fraction as derived from the flow meters.

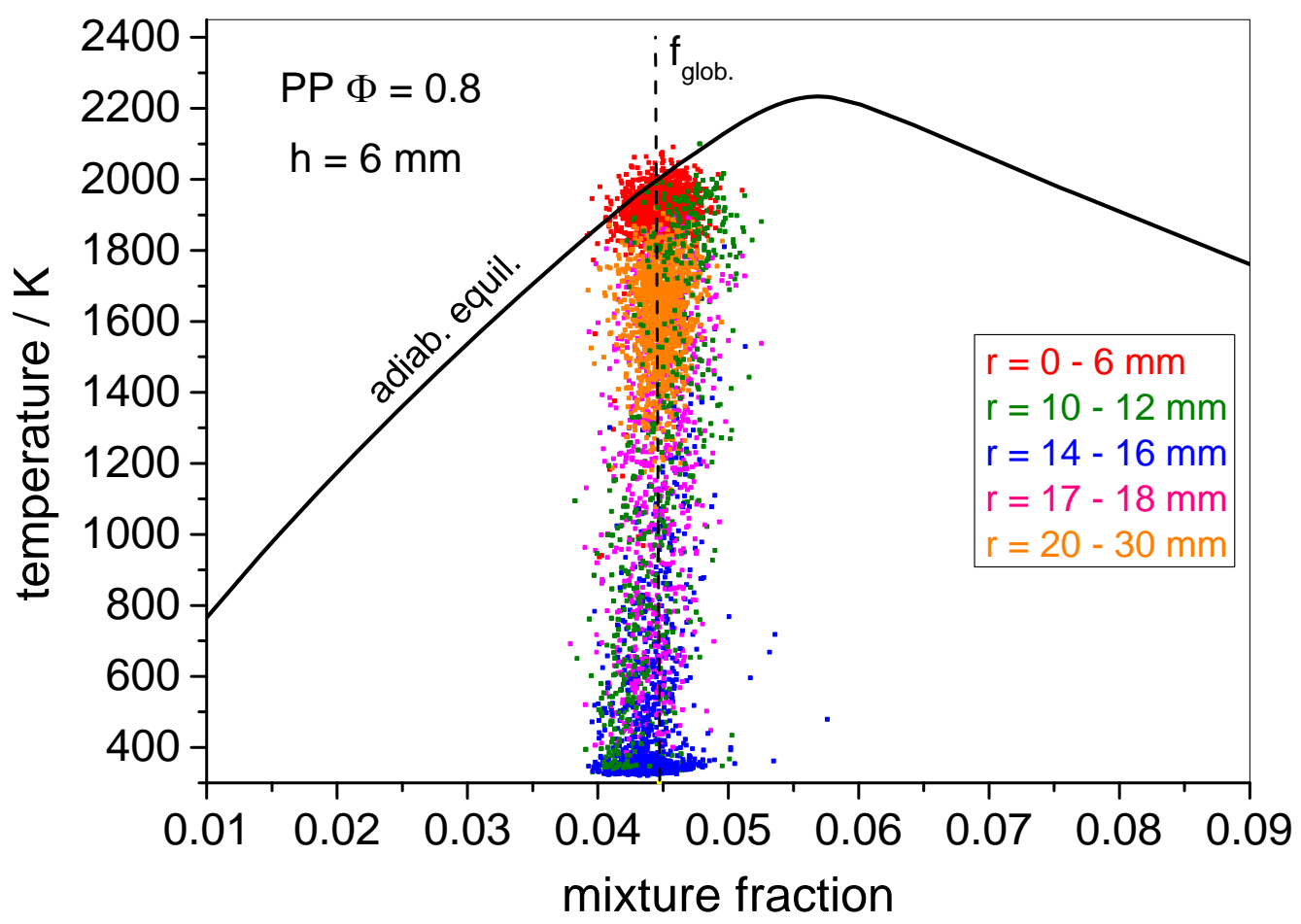


Fig.7: Scatterplot of $\mathrm{H}_{2} \mathrm{O}$ mole fraction vs. temperature for flame PP08 at $\mathrm{h}=6 \mathrm{~mm}$. IRZ and ORZ mean inner and outer recirculation zone, respectively. ISL is inner shear layer, OSL outer shear layer. The cross marks the state of adiabatic equilibrium.

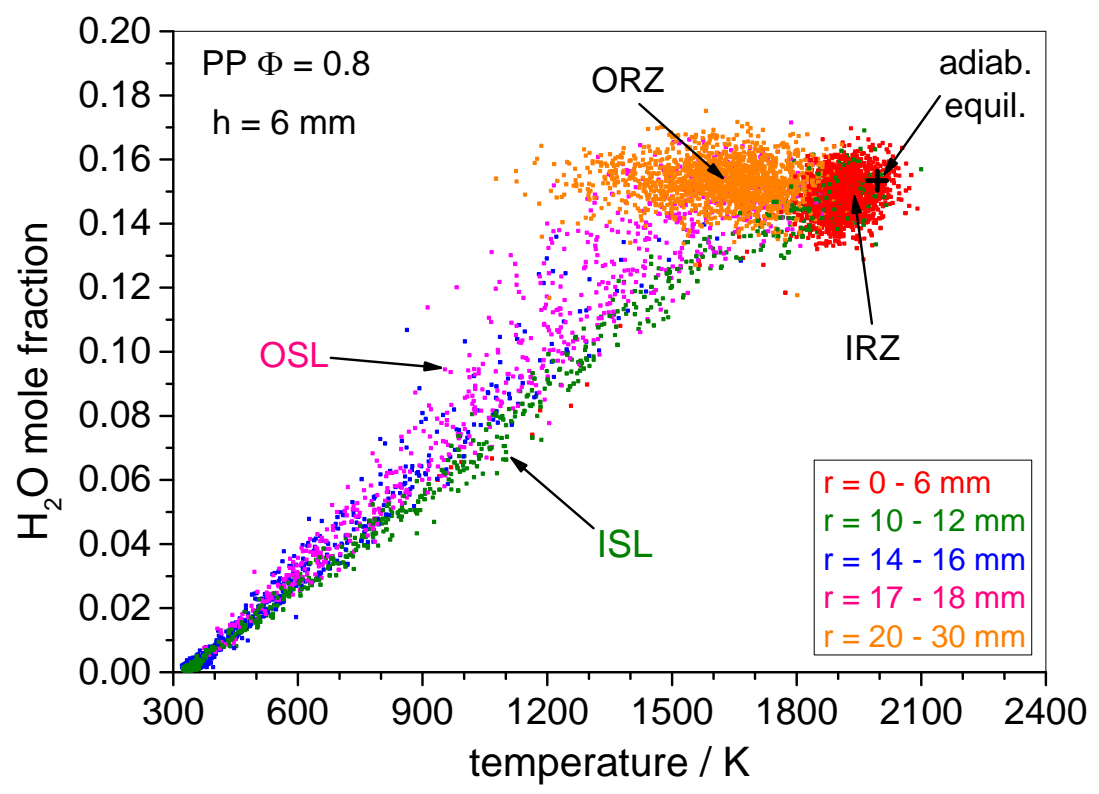


Fig.8: 2D plot of the mean temperature distribution of flame PP08 generated by interpolation between the measurement points.

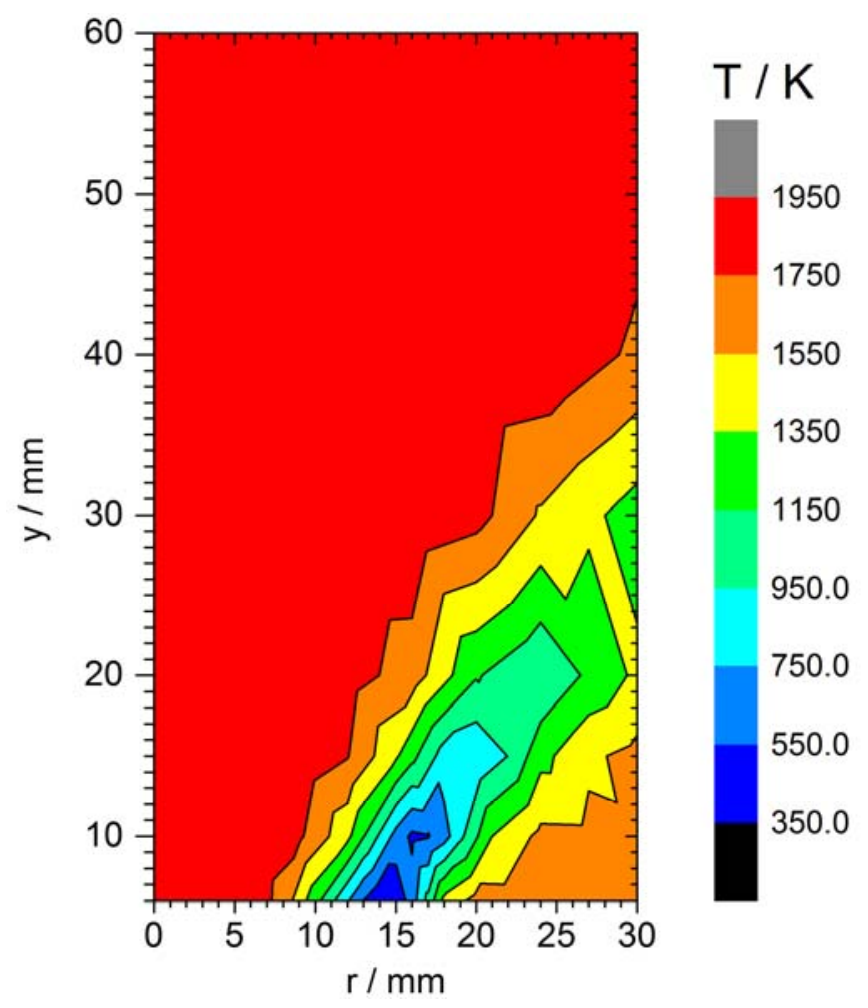


Fig.9: Scatterplot of temperature vs. mixture fraction at $\mathrm{h}=6 \mathrm{~mm}$ for the flames PP09 (upper frame) and TP09 (lower frame).
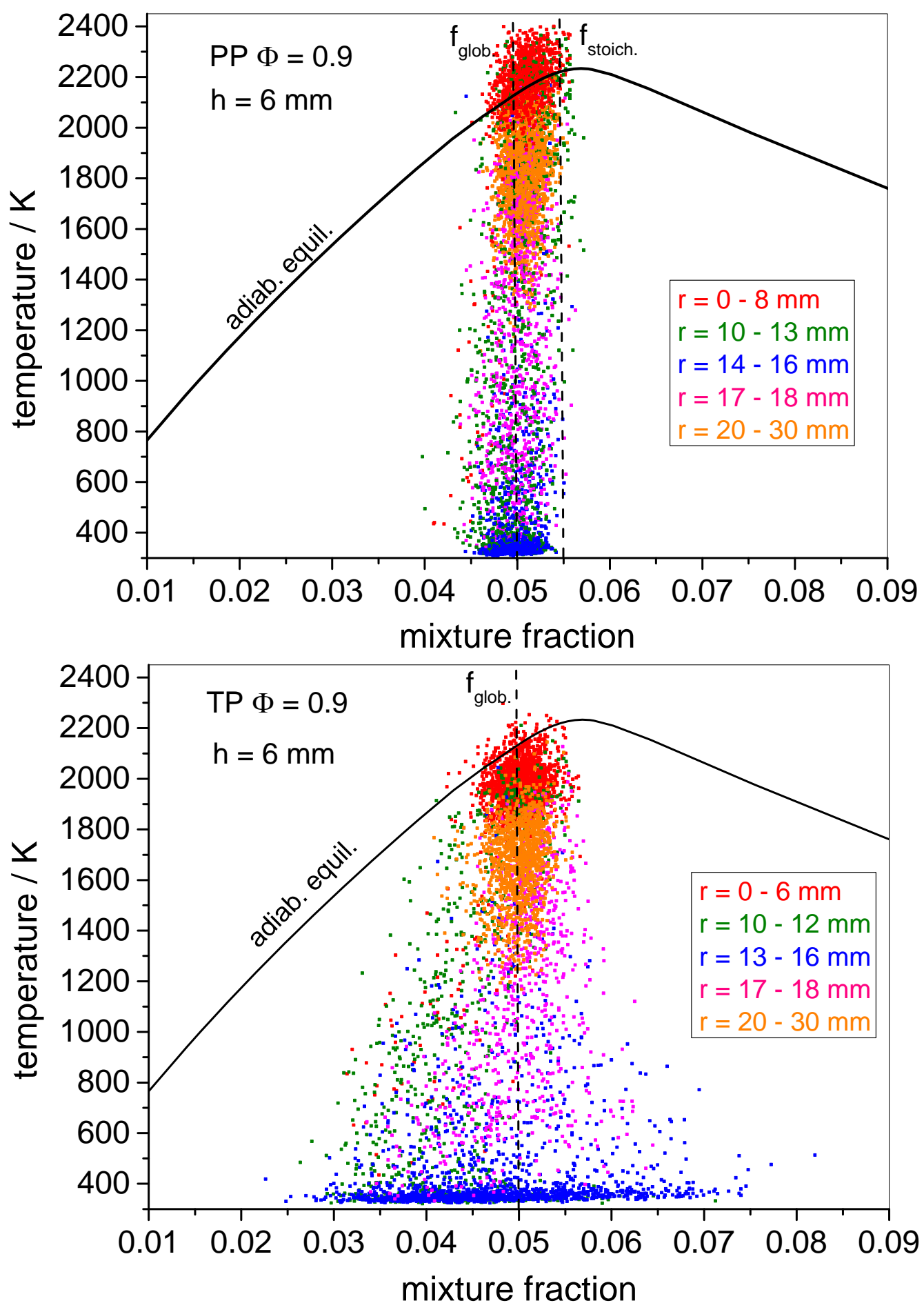
Fig. 10: Scatterplots of $\mathrm{H}_{2} \mathrm{O}$ mole fraction vs. mixture fraction at $\mathrm{h}=30 \mathrm{~mm}$ for the flames PP09 and TP09.
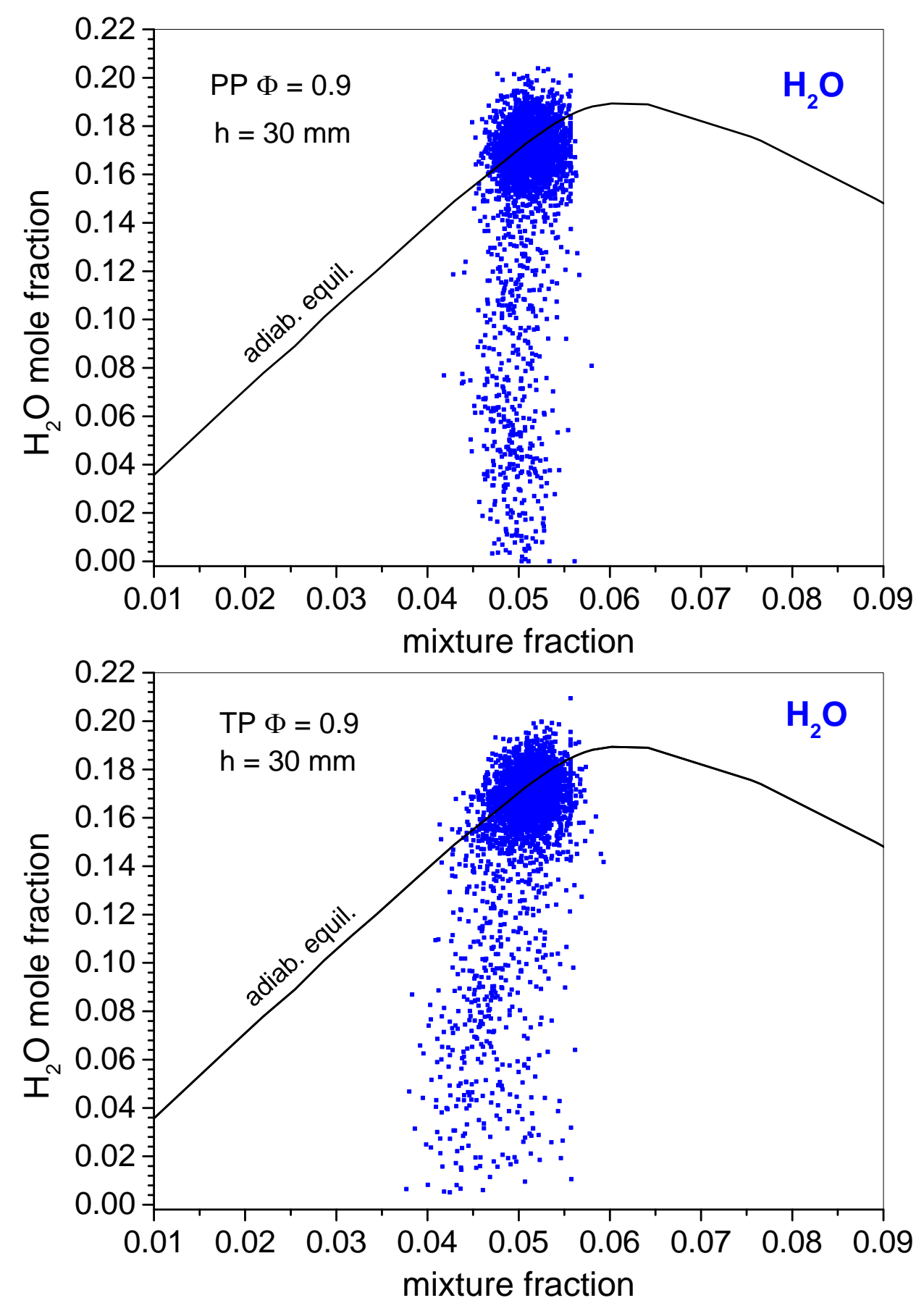
Fig.11: 2D plots of mean reaction progress of the flames PP09 and TP09 generated by interpolation between the measurement locations.
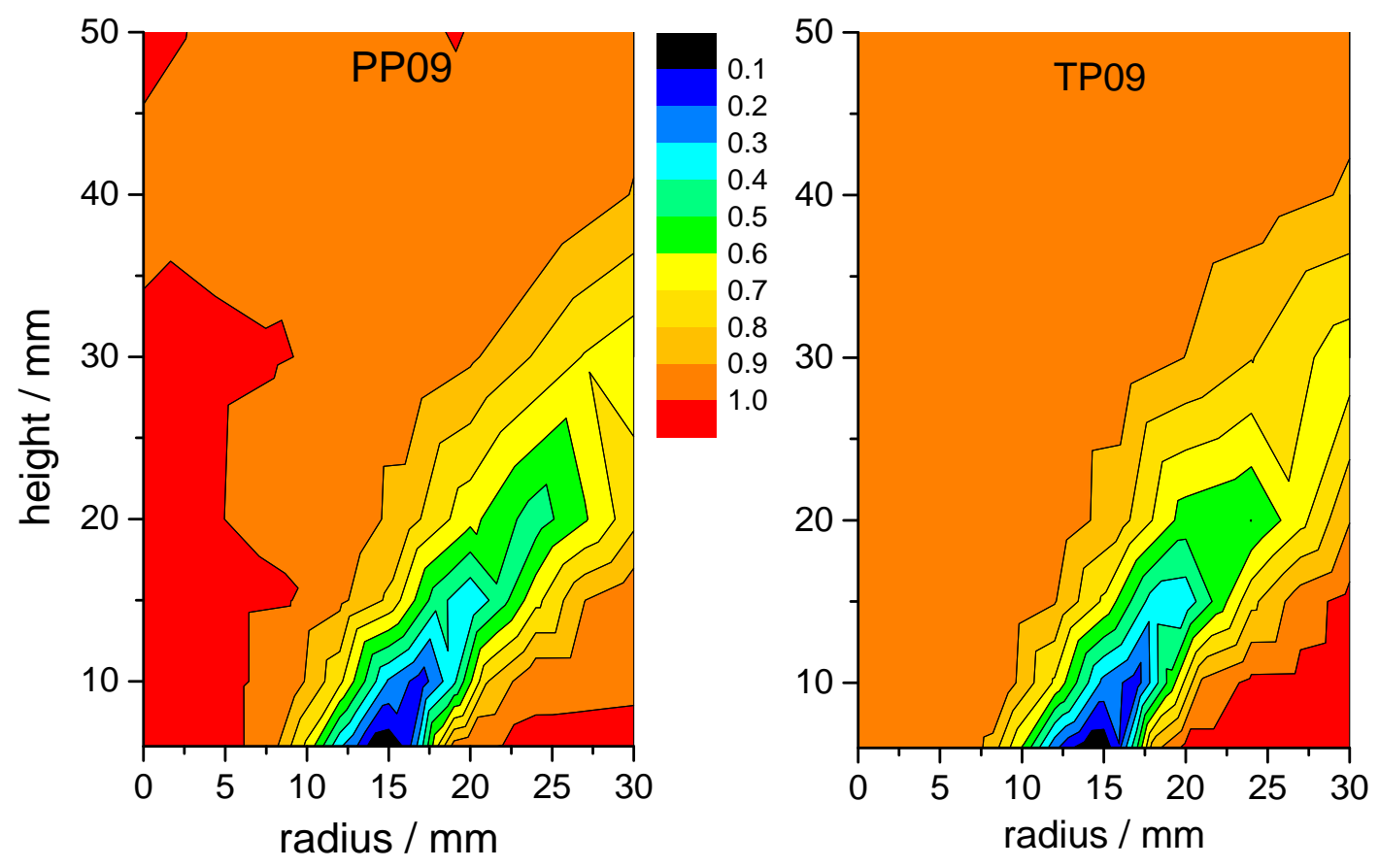
Fig.12: Radial profiles of the mean $\mathrm{H}_{2} \mathrm{O}$ mole fractions of the flames PP09 and TP09 at different heights.

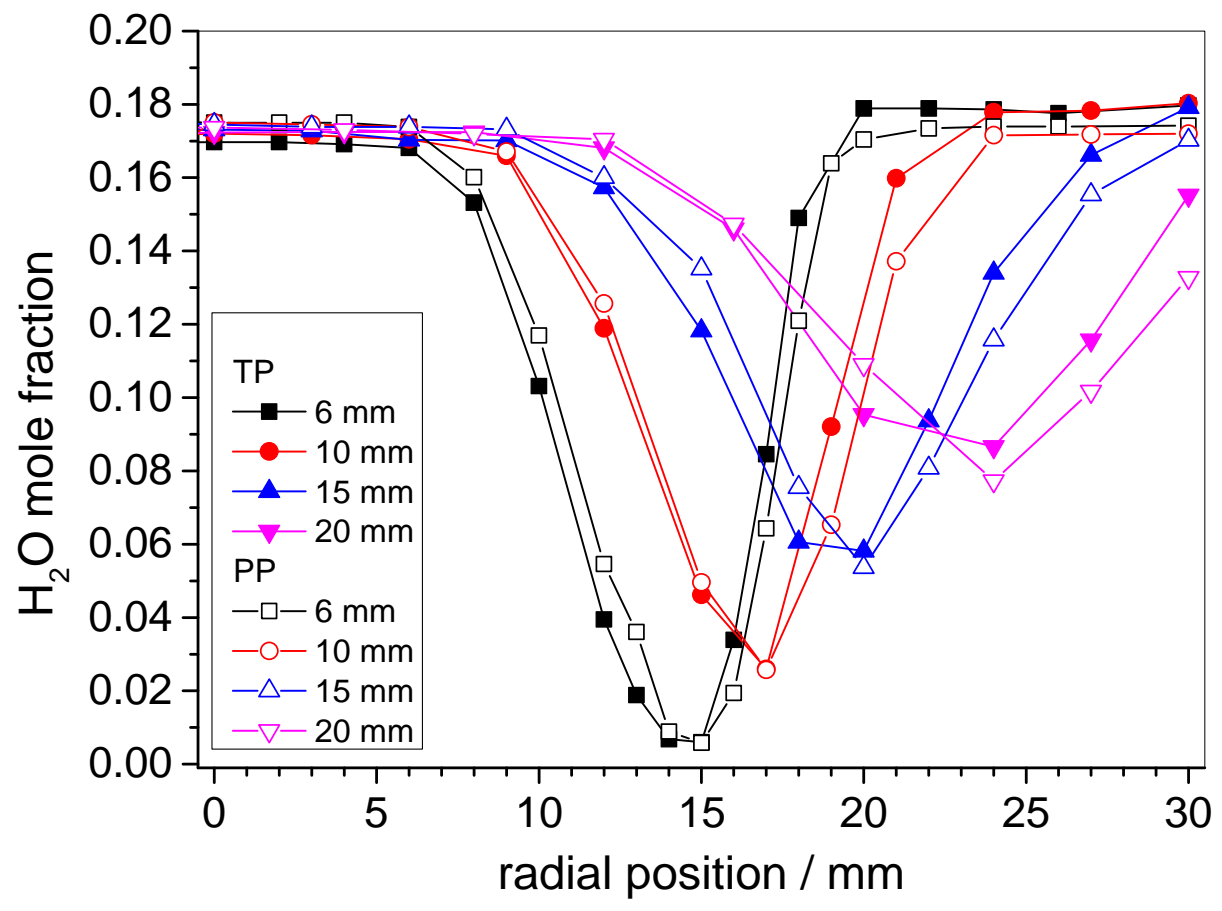


Fig.13: Scatterplot of CO mole fraction vs temperature at $\mathrm{h}=6 \mathrm{~mm}$ for the flame PP09. The largest $\mathrm{CO}$ concentrations are present in the inner shear layer (ISL).

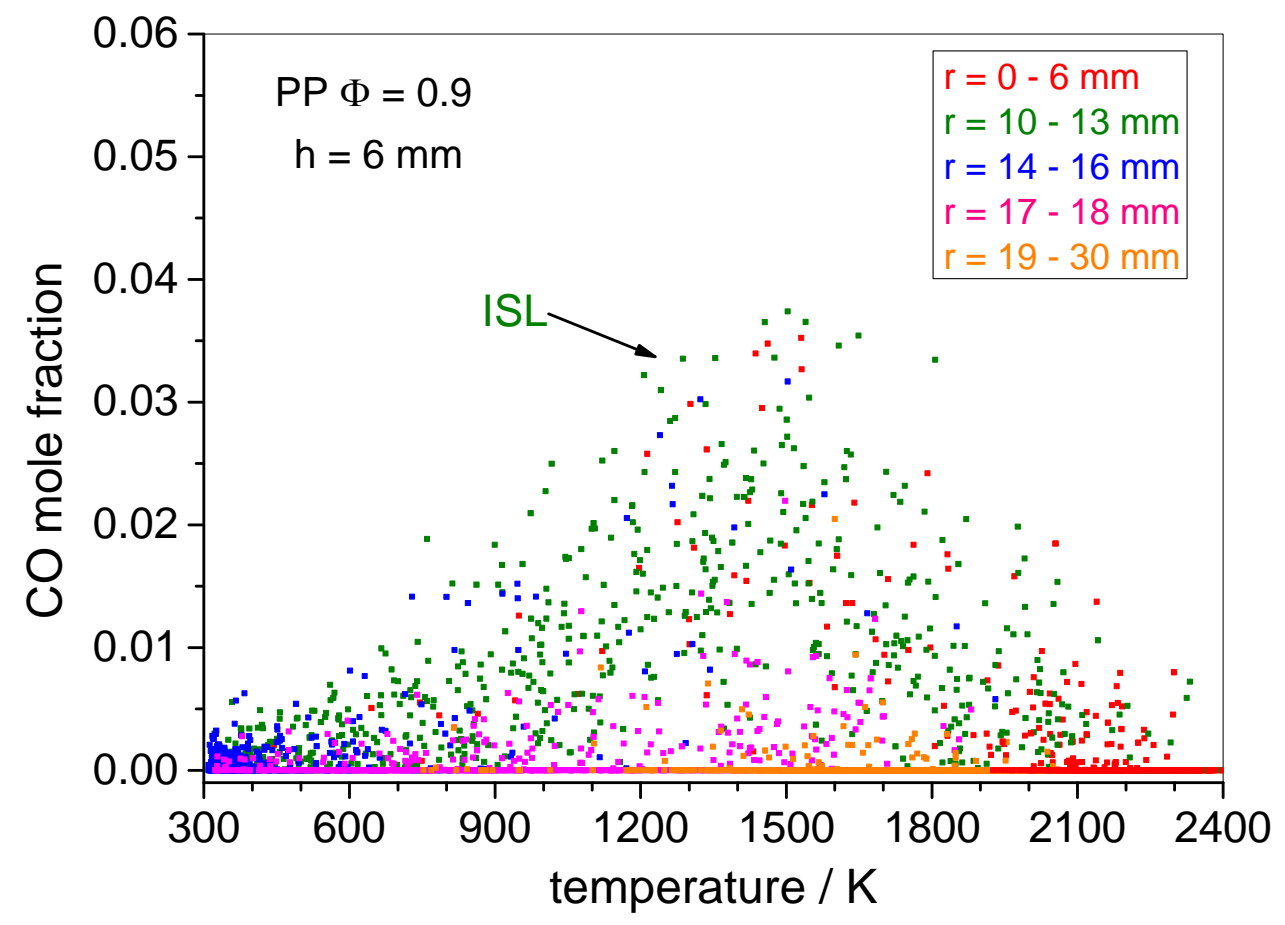


Fig.14: Conditionally averaged $\mathrm{CO}$ mole fractions at $\mathrm{h}=6$ and $10 \mathrm{~mm}$ for the flames with $\varphi=$ 0.9 .
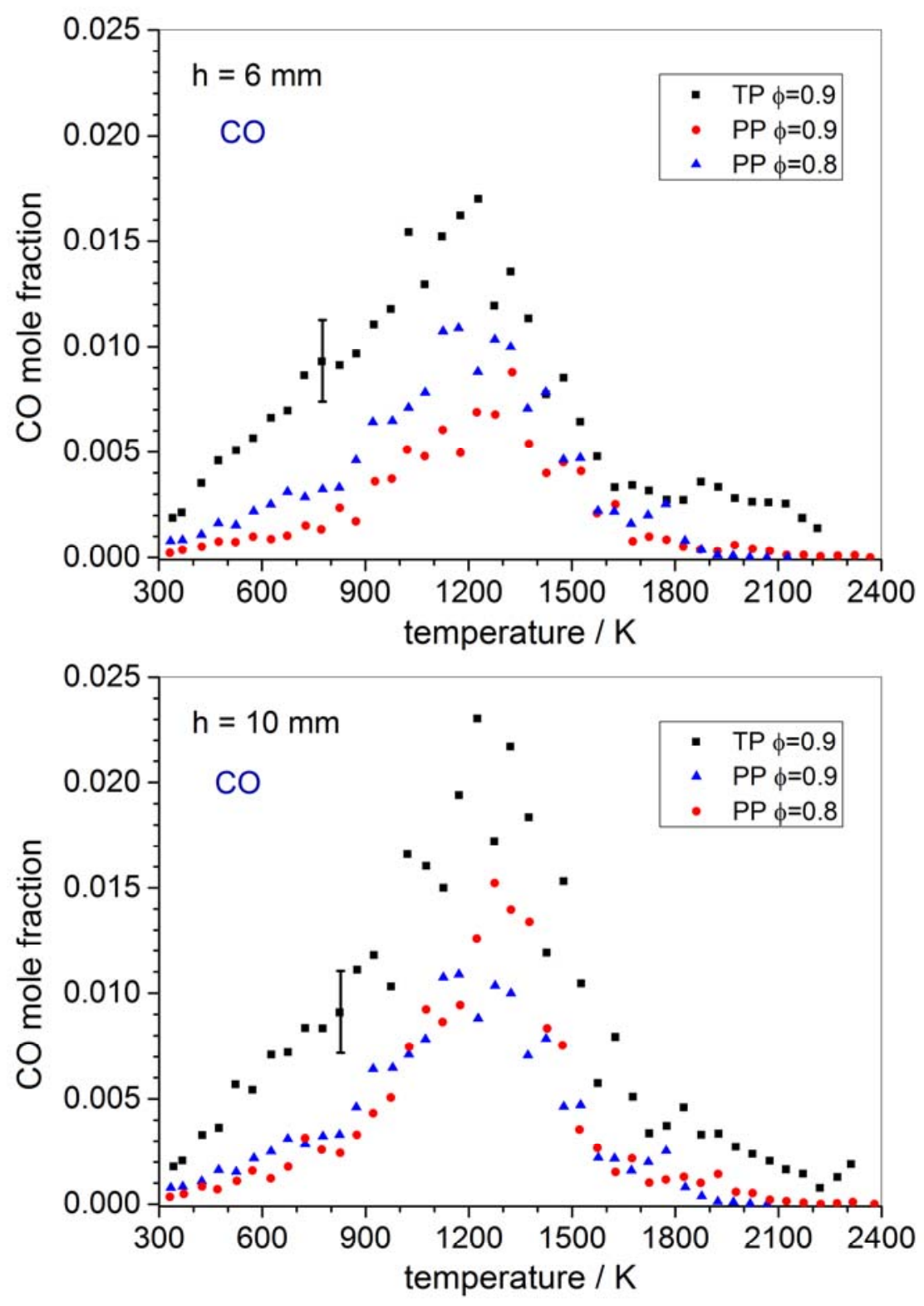
Fig.15: Radial profiles of the mean CO mole fractions recorded at different heights.
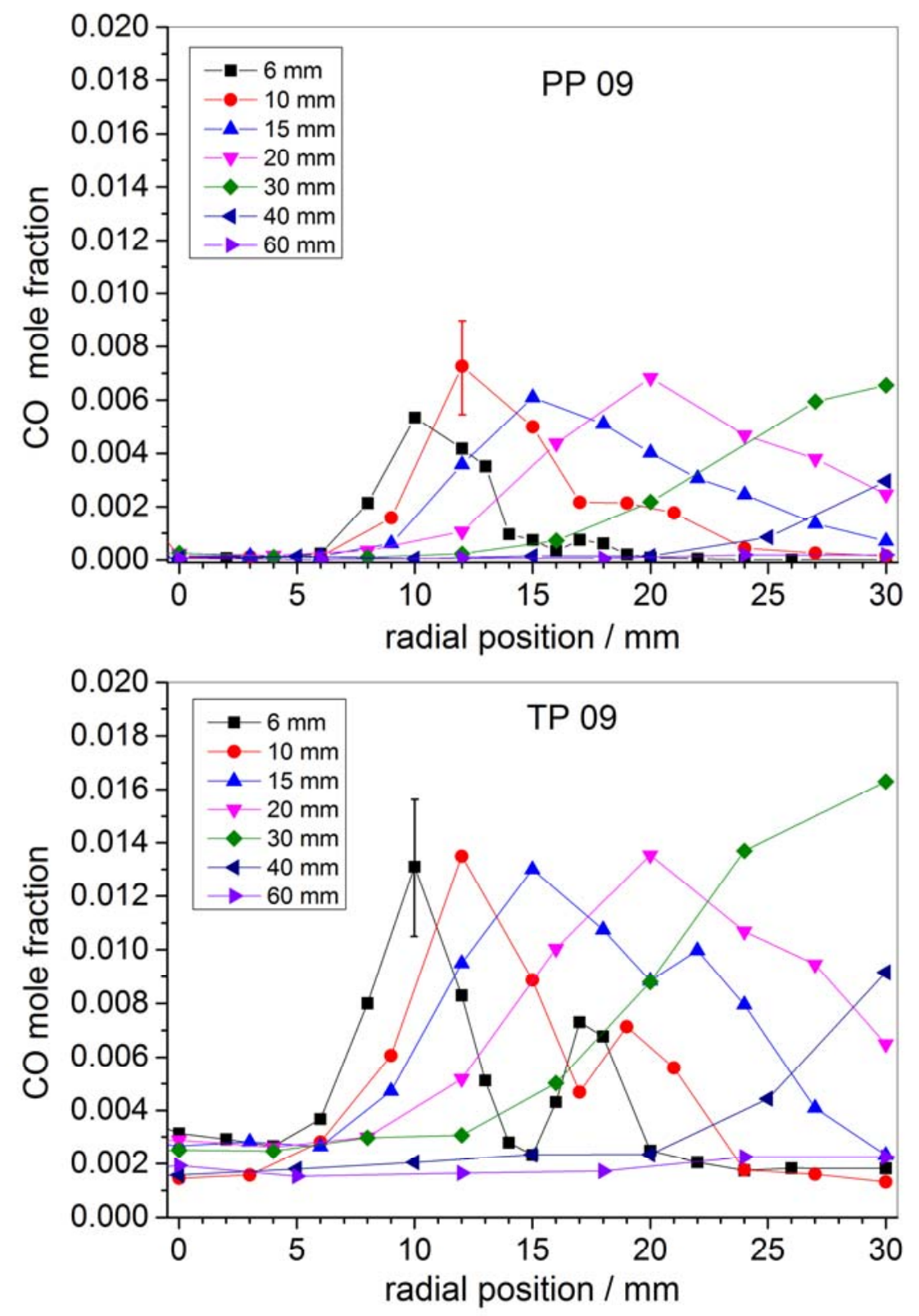